\title{
Autophagy in cancers including brain tumors: role of MicroRNAs
}

\author{
Mohammad Hossein Pourhanifeh ${ }^{1}$, Maryam Mahjoubin-Tehrann ${ }^{2,3}$, Mohammad Reza Karimzadeh4,

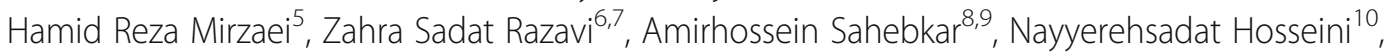 \\ Hamed Mirzaei ${ }^{11^{*}}$ and Michael R. Hamblin ${ }^{12^{*}}$
}

\begin{abstract}
Autophagy has a crucial role in many cancers, including brain tumors. Several types of endogenous molecules (e.g. microRNAs, AKT, PTEN, p53, EGFR, and NF1) can modulate the process of autophagy. Recently miRNAs (small noncoding RNAs) have been found to play a vital role in the regulation of different cellular and molecular processes, such as autophagy. Deregulation of these molecules is associated with the development and progression of different pathological conditions, including brain tumors. It was found that miRNAs are epigenetic regulators, which influence the level of proteins coded by the targeted mRNAs with any modification of the genetic sequences. It has been revealed that various miRNAs (e.g., miR-7-1-3p, miR-340, miR-17, miR-30a, miR-224-3p, and miR-93), as epigenetic regulators, can modulate autophagy pathways within brain tumors. A deeper understanding of the underlying molecular targets of miRNAs, and their function in autophagy pathways could contribute to the development of new treatment methods for patients with brain tumors. In this review, we summarize the various miRNAs, which are involved in regulating autophagy in brain tumors. Moreover, we highlight the role of miRNAs in autophagy-related pathways in different cancers.
\end{abstract}

Keywords: Brain tumors, Autophagy, MicroRNAs

\section{Background}

Brain tumors arise from a wide variety of cell types, which give rise to tumors with different degrees of malignancy and invasiveness, and can afflict both adults and children [1,2]. Despite the low incidence of these tumors, they are a leading cause of cancer-associated mortality and morbidity, particularly in young adults and children, where they account for about 20 and 30\% of cancer deaths, respectively. Metastasis to the central nervous system (CNS) is also responsible for deaths in

\footnotetext{
* Correspondence: mirzaei-h@kaums.ac.ir; h.mirzaei2002@gmail.com; HAMBLIN@helix.mgh.harvard.edu

${ }^{11}$ Research Center for Biochemistry and Nutrition in Metabolic Diseases, Institute for Basic Sciences, Kashan University of Medical Sciences, Kashan, Iran

${ }^{12}$ Wellman Center for Photomedicine, Massachusetts General Hospital, Harvard Medical School, 40 Blossom Street, Boston, MA 02114, USA Full list of author information is available at the end of the article
}

patients with other types of malignancies. In 2015, CNS tumors were estimated to represent $2.6 \%$ of cancerrelated deaths as well as $1.4 \%$ of newly diagnosed cancers [3-5].

Because surgical brain tumor resection only leads to survival of a few months (median of 3 months), many studies have been done to improve the effectiveness of treatment, because complete tumor removal is usually impossible [6, 7]. The surgical elimination of the tumor is dependent on the glioma sub-type and its location within the brain [6]. However, although additional chemotherapy and radiotherapy can prolong median survival up to more than 1 year, tumor cells still develop resistance mechanisms to these therapies [8-10]. Identifying the detailed molecular mechanisms involved in tumor progression could reveal novel approaches to developing more effective therapies. 
Several studies have revealed the contribution of autophagy in the pathogenesis of brain tumors $[11,12]$. Autophagy is known to a well-conserved cellular pathway designed for recycling and degrading damaged or denatured proteins, together with long-lived or shortlived intracellular organelles [13, 14]. The autophagy process can be categorized into 3 sub-types called, micro-autophagy, macroautophagy, and chaperonemediated autophagy [15]. Autophagy plays important roles in many biological functions ranging from embryonic development to cellular survival [16]. Dysfunction of the autophagic process has been correlated with a wide range of age-related diseases, such as CNS-related disorders and cancers [17]. In recent years, autophagy has begun to be investigated as a therapeutic target in several malignancies, such as breast cancer [18] and melanoma $[19,20]$. There are currently a few anticancer treatments which act on autophagy pathways. Fortunately, compounds that directly or indirectly modulate autophagy are currently being studied in the context of phase I and phase II clinical trials [21]. Additionally, the regulation of autophagy has also been identified as an approach to the treatment of brain tumors in both children and adults [22-25].

Nevertheless, the precise role of autophagy in pediatric CNS tumors is not completely understood, which highlights the need to reveal additional details of autophagyrelated processes to assess whether the contribution of autophagy inhibition to cancer therapy is a valid approach [26]. It has been shown that various cellular and molecular mechanisms are associated with autophagyrelated processes in brain tumors and also in other different cancers. Along with genetic mechanisms, epigenetic mechanisms (e.g., miRNA networks) play major roles in the regulation of autophagy-related processes.

MicroRNAs (miRNAs) are short non-coding RNAs that bind to the $3^{\prime}$ untranslated regions of messenger RNAs (mRNAs) [27]. In fact, miRNAs can modulate the expression of more than $50 \%$ of each gene because each individual miRNA is able to target several different mRNAs [28, 29]. Therefore, the deregulated expression of miRNAs is likely to be related to the pathogenesis of many malignancies, such as brain tumors [30]. A variety of miRNAs are able to modulate autophagy, and its related mechanisms in various cancers including brain tumors [31-35]. Taken together, many reports suggest that a better understanding of the underlying molecular mediators (i.e. miRNAs), and their functions in autophagy pathways, could contribute to the discovery and advancement of novel treatment approaches for patients with brain tumors. Some reviews explained the role of miRNAs and autophagy in generally cancers [36, 37]. However until now, their specific roles in brain tumors have not been described. Herein, for first time, we summarize the various miRNAs which are involved in regulating autophagy in brain tumors. Moreover, we highlight the contribution of miRNAs to autophagyrelated mechanisms in different cancers.

\section{Autophagy mechanisms}

Autophagy (literally self-eating) is the conserved, regulated mechanism for an orderly degradation and recycling of various cellular elements that are damaged or unnecessary [38]. It is known that autophagy can be induced in mammalian cells by different factors, such as oxidative stress that leads to endoplasmic reticulum (ER) stress. During ER stress, autophagy serves as an essential protective response [39]. Autophagy was first fully investigated in yeast cells, and the terminolgy "autophagy genes, ATG" was agreed upon to describe the proteins involved. The two main regulatory pathways of the autophagy machinery include the ATG5/7-independent and ATG5/7-dependent pathways [40, 41].

According to the literature, the Unc-51-like kinase (ULK) complex containing several proteins, such as ATG101, ATG13, FIP200 (FAK-family interacting protein of $200 \mathrm{kDa}$ ), as well as ULK1/2 (mammalian ortholog of yeast ATG1) initiates conventional ATG5/7dependent autophagy [42, 43]. Under non-stressed conditions, ULK $1 / 2$ is phosphorylated by the mammalian target of the rapamycin complex 1 (mTORC1) resulting in inactivation of the ULK complex [44]. On the other hand, the nutrient-sensitive mTORC1 is inhibited under nutrient-limiting conditions, and the ULK complex subsequently remains non-phosphorylated, and is therefore activated [45]. After activation, translocation of the ULK complex to the phagophore, has been shown to occur. After this, the class-III phosphatidylinositol 3-kinase (PI3K) complex containing VPS34 (phosphatidylinositol 3-kinase Vps34), VPS15, Beclin1, as well as ATG14 proteins, becomes activated [46]. This results in the formation of the mature autophagosome, after phagophore closure and extension. Two different ubiquitin-like conjugation systems, microtubule-related protein 1 light chain 3 (LC3) and the ATG5-ATG12 system, are the key modulators of the elongation and closure of the autophagosomal membrane [47-49]. In addition, ATG7 (E1-like enzyme) can activate ATG12, which is then transported into the ATG10 (E2-like enzyme) to eventually conjugate with ATG5 in the ATG5-ATG12 pathway. The non-covalent interaction of the ATG5-ATG12 complex with ATG16L leads to the formation of a large multimeric (E3-like) complex. This tripartite complex is capable of conjugating LC3 to phosphatidyl-ethanolamine (PE) to produce a LC3-PE conjugate (which is called LC3-II). LC3-II is then loaded into the phagophore [50-52]. In order to monitor the progression of autophagy, LC3-II protein is frequently employed as a biomarker, since it is localized to both the 
outer and inner membranes of autophagosomes and phagophores [53, 54].

Lysosomes, which are the degrading machinery in autophagy, are related to MTORC1 activation via the Rag/RRAG GTPase pathways. It has been shown that a MTORC1 inhibitor could suppress lysosomal degradation and increase lysosomal permeability [55]. The fusion of lysosomes with autophagosomes is the last step in the autophagy degradation cascade, which is triggered via three different sets of protein families: (a) RabGTPases (Rab7 protein) [56, 57]; (b) HOPS (homotypic fusion \& the protein sorting tethering complex); and (c) the SNAREs (soluble N-ethylmaleimide-sensitive agent attachment protein receptors) [58-60]. Therefore, 3 distinct SNARE proteins; the vesicle-associated membrane protein 8 (VAMP8); synaptosomal-associated protein 29 (SNAP29); and syntaxin 17 (STX17) can all induce lysosome-autophagosome fusion [61, 62] (Fig. 1).
The mechanism of ATG5/7-independent autophagy has been discussed by Nishida and colleagues (2009) [43]. It was called "alternative autophagy" because ATG7 as well as ATG5 had been thought to be essential for autophagy [43]. The important finding in their study was that etoposide treatment of ATG5-deficient mouse embryonic fibroblasts (MEFs) triggered autophagy to a similar degree as in the wild type ATG5-expressing cells. Additionally, researchers found that PI3K, beclin1, and ULK1 complex played an important role, just as they do in conventional autophagy. Moreover, it was also found that silencing of the ATG5-ATG12 pathway had no effect on alternative autophagy, and that the conventional lipidation of LC3 was carried out by Rab9 activity to allow phagophore extension [43]. Rab9, which usually induces protein transport from the late endosomes to the trans-Golgi membrane, has been suggested to carry out phagophore closure and extension in the alternative

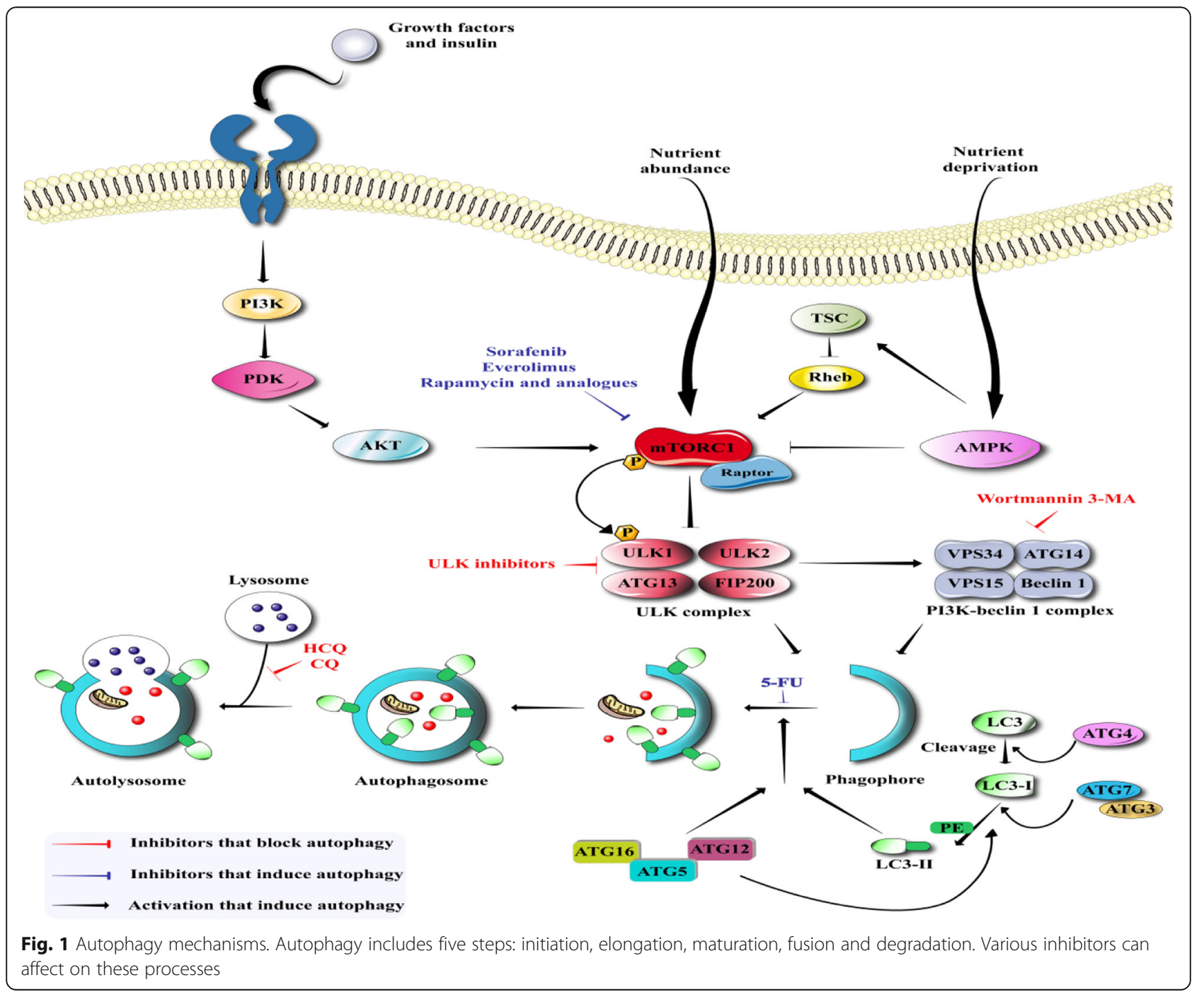


autophagy pathway. This was the same process as carried out by ATG5/ATG7/LC3 in the conventional autophagy pathway [63-65]. There are multiple sources of phagophores in the ATG5/7-dependent autophagy pathway, but in the alternative autophagy pathway, the trans-Golgi cisternae seem to be the origin of the membranes $[43,66,67]$.

Studies have shown that autophagy is a critical quality control function in cellular processes. Autophagy at baseline levels operates to sustain cellular hemostasis. Some organelles undergo selective turnover through the autophagy mechanism. Various autophagy pathways can be distinguished by categorizing the contents of the autophagosomes. These pathways include, lipid droplets (lipophagy), ER (reticulophagy or ERphagy), secretory granules (zymophagy), mitochondria (mitophagy), and even some parts of the nucleus (nucleophagy). Furthermore, proteins that are prone to aggregation (aggrephagy), ribosomes (ribophagy), and pathogens (xenophagy), can be specifically targeted and degraded by autophagic processes [68]. Some types of autophagy function as cellular quality control mechanisms. These might be able to distinguish their substrates, including dysfunctional mitochondria or protein aggregates from their fully functional counterparts. Cargo selection, as well as autophagy regulation, still have mechanistic aspects that remain to be discovered, and this has been a focus of intense research interest in recent years. Recently a genome-wide small interfering RNA screening study was carried out to identify the various mammalian genes that are necessary for selective autophagy. This study discovered 141 candidate genes, of which 96 of them were required for Parkin-mediated mitophagy [69]. It appears that these pathways involve particular cargorecognizing autophagy receptors that link the autophagic membranes to the cargo. These receptors may also interact with specific molecular adaptors, which act as scaffolding proteins. These proteins may help to connect the cargo receptor complex to the core ATG machinery. This connection allows selective sequestration of the substrate. There are other types of autophagy that are based on similar core molecular machinery to the nonselective (starvation-induced) bulk autophagy. On the contrary, specific molecular adapters or autophagy receptors are not necessary for the non-selective autophagy pathway. Autophagy receptors have been proposed as being capable of directing interaction with ATG8/ LC3 family members, as well as the autophagosome cargo via specific (WxxL) sequences [70]. These are usually referred to as LC3 recognition sequences (LRS) or LC3-interacting region (LIR) motifs [71, 72]. By comparing the LIR domains among 20 different autophagy receptors, studies found that the LIR consensus recognition motif comprised a sequence of 8 amino acids. This sequence can be written down as D/E-D/E-D/E-W/F/Y$\mathrm{X}-\mathrm{X}-\mathrm{L} / \mathrm{I} / \mathrm{V}$. This is not, however, an essential condition, because at least one acidic residue upstream of the Wsite exists. On the other hand, the terminal L-site contained a hydrophobic aminoacid residue, L, V, or I [73]. It was found that the LIR motifs of numerous autophagy receptors could all interact with both GABARAP and LC3 family members in vitro. But whether this interaction actually occurs under physiological conditions should be elucidated in most cases. It may be the case that all the LIR-containing proteins are not necessarily autophagy-cargo receptors. For example, there are a number of LIR proteins, such as ATG4B as well as ATG3, which could function in the autophagic membrane to produce autophagosomes [74, 75]. Other proteins, such as the coiled-coil domain-containing protein 1 (FYCO1) and FYVE can interact with LC3 to promote autophagosome maturation [76]. Other proteins, including Dishevelled, act as adaptors in the Wnt signaling pathway, and may exploit an LIR motif for their degradation [77]. These adaptor proteins have not yet been completely described, but they appear to interact with autophagy receptors and act as scaffold proteins for the assembly of the ATG machinery. This allows the production of autophagosomes that surround the cargo that is required to be degraded. ATG11 and ALFY are examples of these autophagy adaptors [78, 79]. The cytoplasm-to-vacuole targeting (Cvt) pathway mediates the transportation of some vacuolar hydrolases, such as amino-peptidase 4 (Ape4), $\alpha$-mannosidase (Ams1), aminopeptidase 1 (Ape1), and Ty1 transposon (in yeast) into the vacuole [80, 81]. Ape1 is generated from a cytosolic precursor (prApe1), which undergoes multimerization into higher order Ape1 oligomers. Ams1, Ty1, and Ape4 then associate with the Ape1 oligomer to generate the fully assembled Cvt complex, which is sequestered in a small autophagosome-like vesicle. Sequestering the Cvt complex inside the Cvt vesicle is a multistage process, requiring the autophagy receptor ATG19 that promotes ATG8 binding to PAS, and to adaptor protein ATG11 (Fig. 2a) [82]. ATG11 functions as a scaffold protein by controlling the ATG9 reservoir, and allowing the Cvt complex to bind to PAS in an actin-dependent manner, and consequently forming the ATG1/ULK complex [83]. ATG20, ATG21, and ATG24 are PI3P-binding proteins, which have been found to be necessary for the Cvt function, however, the exact functions of these proteins is not yet clear. Surprisingly, over-expression of ATG11 led to greater ATG9 and ATG8 binding to PAS and more Cvt vesicles [84]. These results suggest that the level of ATG11 can selectively control the autophagy rate. ATG11 can also control the size of the cargoloaded autophagosomes in yeast [85]. Some studies have shown that ATG11 can contribute to other types of 


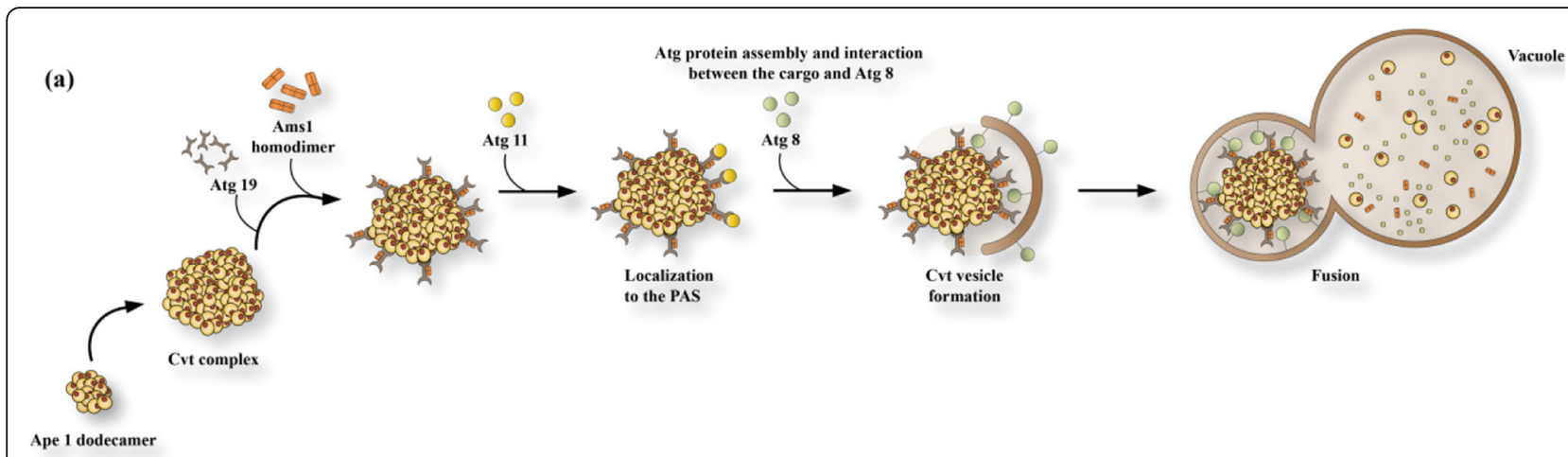

(b)

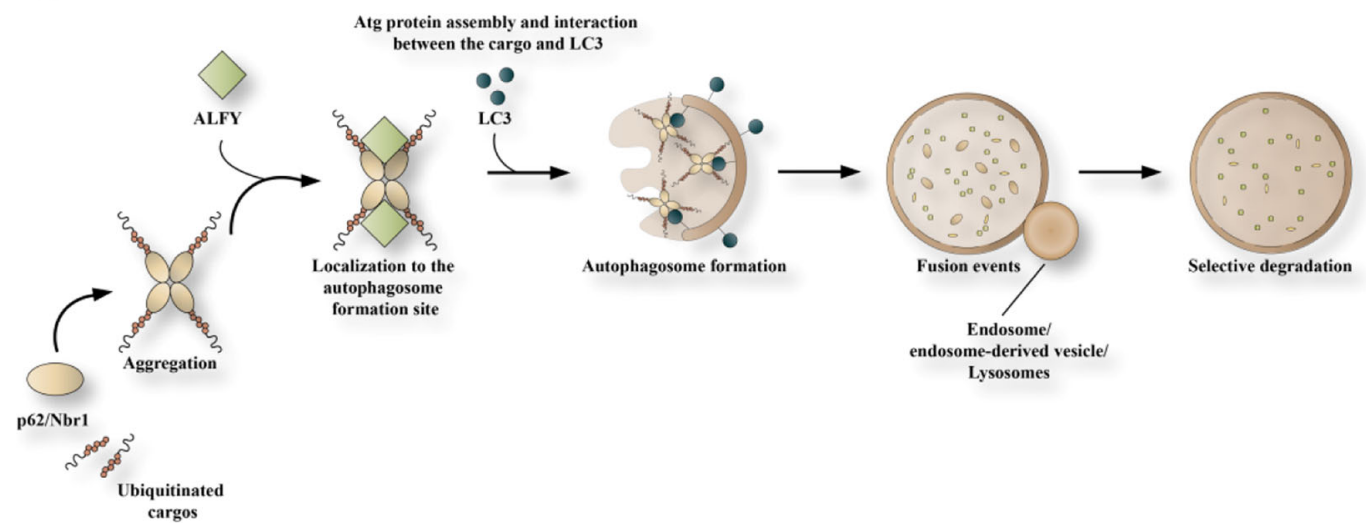

Fig. 2 Mechanisms for selective autophagy. a Targeting pathway from the cytoplasm to the vacuole (Cvt). Ape1 is generated as a cytoplasmic precursor protein alongside a propeptide. The molecule will rapidly oligomerize into dodecamers. These dodecamers will link to each other to create higher-order composites. ATG19 as an autophagy receptor directly attaches to this complex and leads to another Cvt pathway cargo named Ams1 resulting in the formation of the Cvt complex and ATG19 interaction with an autophagy adaptor ATG11. The Cvt complex is transported to the location wherein the double-membrane vesicle will be created. ATG11 binds the ATG proteins required to generate Cvt vesicles. However, ATG19 direct binding to ATG8 allows unique sequestration of the Cvt complex into vesicles. $\mathbf{b}$ Scheme for p62 as well as NBR1 acting as autophagy receptors along with the ubiquitinated cargos. Furthermore, P62 and also NBR1 bind to the ubiquitinated cargo through their ubiquitin-associated (UBA) domain. This interaction initiates aggregate generation via oligomerization of p62 through its Bem1p (PB1) and Phox domains. p62 interacts with autophagy-linked FYVE protein (ALFY) to activate ATG5 and bind PI3P, as well as direct binding to LC3. These mechanisms seem to control and activate the ATG function along with the ubiquitinated cargos, and specifically sequester them inside autophagosomes, similar to the Cvt pathway

selective autophagy, including pexophagy and mitophagy. The individual autophagy receptors participating in different ATG11-dependent types of selective autophagy vary, because ATG32 is necessary for mitophagy, while ATG30 is required for pexophagy $[86,87]$. Therefore, these receptors possess an ATG8-binding LIR motif similar to ATG19, that governs the interaction with ATG11. It seems that mammalian cells do not have the ATG11 homologue. More investigations are required to define the molecular mechanisms that govern the sequestering as well as targeting the various cargoes to be broken down by autophagy in different eukaryotes. The Cvt pathway machinery appears to be similar to the mammalian autophagy, named aggrephagy. This entails the degradation of misfolded and unwanted proteins via assembling them into ubiquitinated aggregates. Thus, aggregation of the substrates (prApe1 or misfolded proteins) is essential before sequestering them into the Cvt vesicles or autophagosomes [88]. Aggregate-containing autophagosomes, similar to Cvt vesicles, seem to not contain any cytosolic elements, demonstrating the wellcontrolled expansion of the vesicle membrane surrounding its cargo [78]. Besides, aggrephagy is dependent on the unique functions of proteins that select the substrate [89]. The p62 autophagy receptor and adjacent BRCA1 gene (NBR1) bind the ubiquitinated protein aggregates via an ubiquitin-associated (UBA) domain, as well as LC3, through their LIR motifs. This process ensures the selective autophagic breakdown of the ubiquitinated proteins (Fig. 2b) [90].

p62 and NBR1 also include a Bem1p (PB1) domain and an N-terminal Phox by which they can be 
oligomerized, or interact with PB1-containing binding partners [73]. Moreover, p62 has been implicated as a cargo receptor for protein aggregates in the autophagic breakdown of additional ubiquitinated substrates. These substrates include viral capsid proteins, intracellular bacteria, peroxisomes, midbody remnants formed after cytokinesis, bactericidal precursor proteins, and damaged mitochondria [91]. It has been recently found that the PB1 domain was necessary for p62 to restrict the autophagosome genesis site in the vicinity of the ER. It was suggested that PB1 may target the ubiquitinated cargos to the location of autophagosome formation, or alternatively to improve the assembly of ATG complexes at the site [91].

\section{MicroRNA biogenesis}

MicroRNAs are non-coding single-stranded RNA molecules with a length of approximately 17-25 nt. These molecules modulate biological processes by posttranscriptional gene silencing [92]. Necrotic cells are able to release the miRNAs as naked oligonucleotides, or else they are secreted contained in extracellular vesicles. Furthermore, researchers have detected circulating miRNAs (c-miRNAs) in many body fluids, such as cerebrospinal fluid (CSF). It has been proposed that these c-miRNAs play a role in intercellular communication, and thus can possibly affect various cellular processes at a molecular level, such as cell growth and invasiveness, and can also affect drug resistance in the recipient target cells [93, 94].

Long primary pri-miRNAs or miRNAs are usually transcribed from miRNA genes by RNA polymerase II [95]. Pri-miRNAs may occasionally produce several different functional miRNAs [95]. In order to produce hairpin-structured pre-miRNAs, a core ribonuclease complex, such as Drosha or the respective modulatory sub-unit DGCR8 is used to process them in the nucleus. Following cleavage, these hairpin-structured premiRNAs are transferred from the nucleus into the cytoplasm. Moreover, further cleavage of the pre-miRNA hairpin structure in the cytoplasm is carried out by DICER protein, resulting in the formation of long miRNA duplexes. These duplexes are loaded into the RNA-induced silencing complex (RISC). In addition, Argonaute (AGO) proteins are essential elements of the RISC that direct mature single-stranded miRNAs to their target mRNAs. However, the destiny of the targeted mRNA is governed by the interrelationship between the miRNA response elements (MRE) and the mature miRNA seed sequences. Therefore, base-pairing of the target mRNA to the guide miRNA leads to its endonuclease-mediated cleavage in a slicer-dependent manner. The degradation process can be proceeded by miRNA-mediated deadenylation and/or de-capping of the target mRNA, while the translation machinery may be blocked by partial complementary binding (Fig. 3) [96, 97].

\section{Regulation of autophagy by microRNAs in cancer}

Over the past decade, it has been found that miRNAs are able to control a number of ATGs (and their respective modulators) at various steps of the autophagy process, including vesicle nucleation, induction, retrieval, fusion, and finally vesicle elongation (Fig. 3) [98]. The first step in the induction of autophagy is triggered by ULK complex activation. This complex includes the components, ULK1/2, FIP200, and FIP200 [98, 99]. Moreover, ULK1 protein kinase has been considered to be the main initiator of the autophagic process. In nutrient-rich conditions, mTOR is able to phosphorylate the mammalian ATG13 (mATG13) and ULK1 that together prevent the activation of ULK1 kinase. However, under starvation conditions, mTOR is inactivated which then allows ULK1 to phosphorylate FIP200 and mATG13 as well as itself. This leads to engagement of ATG complexes, like class-III phosphatidylinositol 3kinase (PI3KCIII) to initiate autophagy. In addition, the miR-290-295 cluster was shown to down-regulate ULK1 levels, so that ATG7 inhibited autophagic cell death caused by glucose starvation [100]. Leucine deprivation also repressed expression of miR-106b and miR-20a through repression of the transcription factor c-Myc. Transfection of miR-20a or miR-106b mimics could hamper the leucine deprivation mediated autophagy in C2C12 myoblasts. This mechanistic investigation suggested the probable targeting of ULK1 by miR-106b and miR-20a, as well as directly preventing its expression [101]. A simple chalcone-type flavonoid compound, called isoliquiritigenin can be isolated from liquorice compounds. This flavonoid mediated cell cycle arrest, chemo-sensitization, as well as autophagy in multidrug resistant MCF7 cells. This mechanic investigation suggested that miR-25 was a key target of soliquiritigenin. Moreover, miR-25 suppression caused autophagic cell death via direct ULK1 over-expression [102].

It was reported that miR-126 was down-regulated in malignant mesothelioma tissue, and also that its overexpression inhibited cancer cell growth, probably because of its impact on their metabolism. miR-126 also led to energy deprivation, reduced glucose uptake, and inhibited IRS1, resulting in ULK1 activation [103]. Furthermore, miR-126 also affected other metabolismassociated proteins, including acetyl-CoA-citrate and pyruvate dehydrogenase kinase. These metabolic changes induced by miR-126 resulted in the suppression of tumor growth and activation of autophagy both in vitro and in vivo [103].

It was recently reported that ULK2, which is another up-stream autophagy initiator, is a direct target of miR- 


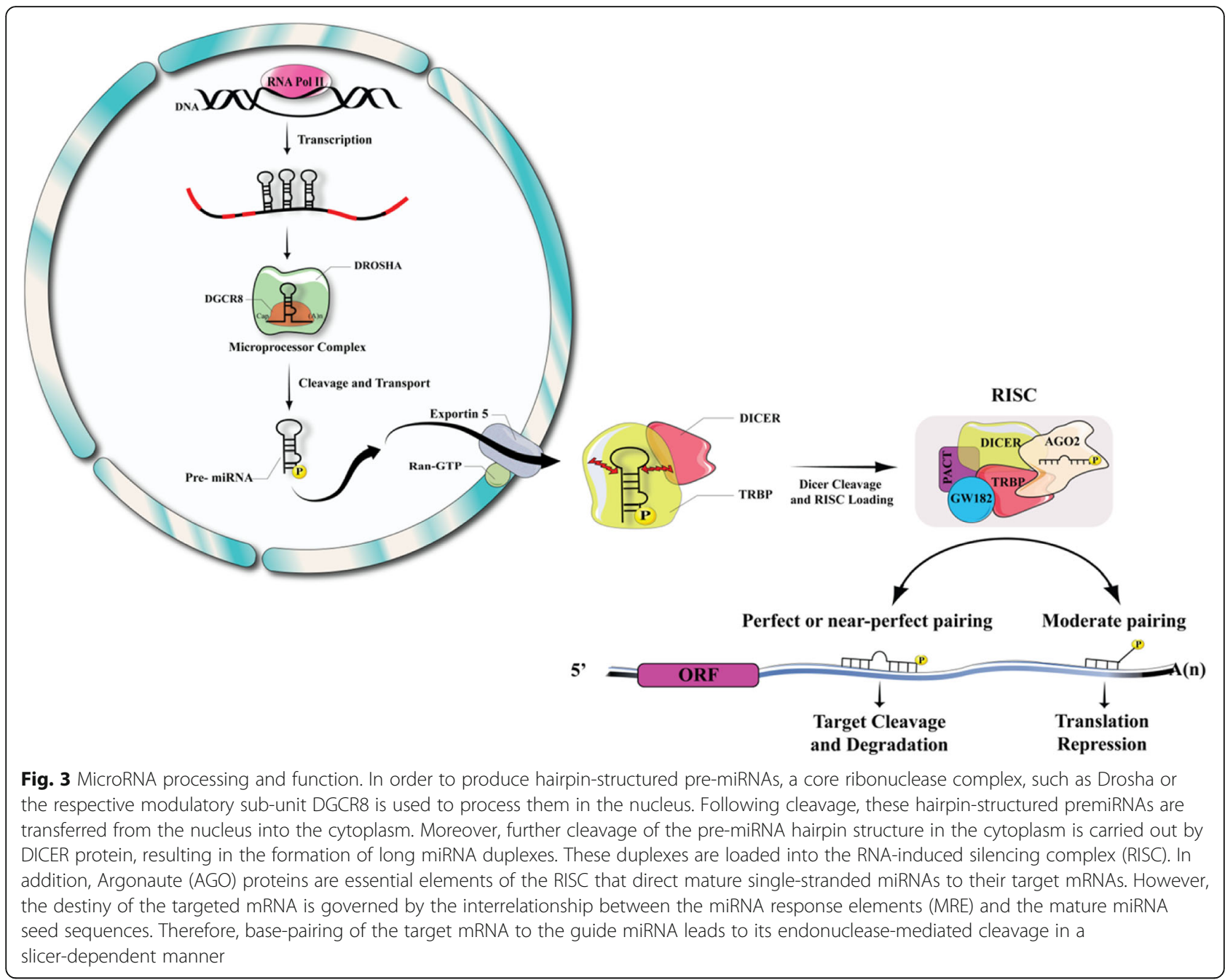

885-3p. Therefore, miR-885-3p may be involved in autophagy modulation [104]. Vesicle nucleation was induced by activation of the class-III PI3K/Beclin-1 complex. This complex has numerous binding partners, including hVPS34, UV-irradiation resistance-associated gene (UVRAG), Bax-interacting factor-1 (BIF-1), ATG14L, and Rubicon. Several miRNAs, including miR-376b, miR30a/b, miR-17-5p, and miR-216a can all hamper Beclin-1 expression, and inhibit vesicle nucleation [105-108]. In one study Huang et al. showed that miR-519a could directly target Beclin-1 [109]. Furthermore, it was shown that miR-374a (as well as miR-630) could inhibit the interaction of UVRAG with Beclin-1, resulting in autophagy activation. ATG14 is a vital component of the class III PI3K/Beclin-1 complex in the nucleation of autophagosomal membranes. ATG14 has also been recognized as a miR-195 target [110]. Moreover, RAB5A a small GTPase, which interacts with Beclin-1 and hVPS34 is able to mediate autophagosome formation. In addition, RAB5A can also be targeted by miRNA-101 to inhibit autophagy, showing that miR-101 can regulate autophagy at the vesicle nucleation stage $[111,112]$. Thirdly, two different ubiquitin-like conjugation mechanisms can act to elongate the vesicle: one is the ATG8-phosphatidyl ethanolamine mechanism and the other is ATG12-ATG5-ATG16L. Several proteins are involved in this process, including ATG7, ATG10, ATG4, ATG5, ATG3, ATG12, ATG16L, as well as microtubule-related protein 1 light chain 3 (LC3). MiR$376 \mathrm{~b}$ and miR-101 can negatively modulate ATG4C and ATG4D expression [107, 112]. MiR-376a was found to have a similar seed sequence and similar targets to miR376b, including Beclin-1 [113] and ATG4C (90).

In hepatocellular carcinoma ( $\mathrm{HCC})$ cells, the conversion of LC3-I into LC3-II is inhibited by miR-375 via targeting of ATG7 [114]. Besides, miR-17 could also decrease the expression of ATG7 in glioblastoma cell lines [115]. Furthermore, RAB5A participates in the conjugation of ATG5 to ATG12 [112]. Thus, miR-101 by targeting RAB5A, could have an impact on both the nucleation and elongation of the vesicles. In addition, 
miR-204 was able to modulate autophagy in renal clear cell carcinoma (RCC) by modulating LC3B [116]. MiR142-3p, miR-106B, and miR-93 can all stimulate autophagy by targeting ATG16L $[117,118]$. Whereas, miR-519a, miR-130a, miR-30a/c, miR-885-3p, miR-630, miR-181a, and miR-374a, can repress autophagy by targeting ATG5-ATG12 conjugation $[119,120]$. The fusion and retrieval process of autophagosomes could be modulated by targeting UVRAG, ATG9, ATG18, as well as ATG2. Many different miRNAs can participate in this final stage of autophagy. Moreover, ATG2B has been established as one of the direct targets of miR-130a [121]. Thus, MiR-34 suppresses autophagy via decreasing ATG9 expression in mammalian cells [122]. Jegga et al. investigated the transcriptional as well as the posttranscriptional modulation of ATGs mediated by miRNAs. They showed that miR-130, 124, 98, 142, and 204 were all involved in the modulation of autophagylysosomal pathway genes. UVRAG is also one of the key molecules in the fusion process. The miRNAs that target UVRAG including miR-374a as well as miR-630, may participate in the modulation of autophagosome-lysosome fusion [109]. There are also some other miRNAs that could be involved in autophagy modulation. BCL-2 binds to Beclin-1, and consequently inhibits Beclin-1dependent autophagy. MiR-182, miR-34a, miR-210, miR-21, and miR-205 can target BCL-2, and are likely to modulate autophagy via the BCL-2/Beclin-1-PI3KIII pathways [123-126]. The p62 protein, called sequestosome 1 (SQSTM1), is a selective substrate for autophagy, and also acts a scaffold in the autophagosome. The miR17/20/93/106 has a common AAGUGC seed motif, and can directly modulate the expression of p62, suggesting a possible role in autophagy modulation [126]. The hypoxia-induced miR-155 can promote autophagy by targeting numerous genes in mTOR signaling pathways, such as RICTOR, RPS6KB2, as well as RHEB [127]. Furthermore, miR-100 is able to enhance autophagy in hepatocellular carcinoma cells via targeting IGF-1R as well as mTOR [128]. Histone deacetylases (HDACs) and histone acetyltransferases (HATs) have a key role in epigenetic regulation by affecting protein acetylation. MiR-9 and miR-206 can modulate HDAC and HAT expression in Waldenstrom macroglobulinemia (WM) cells, leading to autophagy dependent cell death [129]. HDAC6 is a prominent cytoplasmic deacetylase, that targets heat shock protein 90, cortactin, and tubulin. Thus, HDAC6 can modulate cell motility, adhesion, and chaperone function [130]. It has been shown that HDAC6 has a role in carcinogenic transformation and may regulate the epithelial-mesenchymal transition (EMT) in various types of cancer via modulation of major cellular components. Many pieces of evidence suggest that HDAC6 expression is correlated with tumor aggressiveness, anchorage-independent proliferation, and oncogenic transformation [131, 132]. Studies have shown that HDAC6 has a role in the clearance of aggresomes. These studies also pointed out a functional connection between autophagy and HDAC6 [133]. Another study showed that transfection with miR-221 mimics could inhibit HDAC6 expression in pancreatic cancer cells compared to negative controls [133]. In pancreatic cancer cells, the suppression of HDAC6 could mediate autophagy. Down-regulation of miR-221 expression via increasing HDAC6 function could play an oncogenic role in suppressing autophagy and apoptosis in pancreatic cancer cells [133].

Long non-coding RNAs are another member of the class of non-coding RNAs that could have a crucial role in cancer pathogenesis [134]. It is thought that lncRNAs exert their modulating roles via sponging of miRNAs and proteins. The physiological and biological roles of autophagy-regulating lncRNAs in cancer have recently been appreciated. The expression of IncRNAs substantially affects the level of autophagy at various steps of carcinogenesis, and especially in advanced metastatic cancer [134]. It has been proposed that impaired expression of MALAT1 (metastasis associated lung adenocarcinoma transcript 1) regulates autophagy in different cancers such as RTB, HCC, glioma, and GC via modulation of miRNAs, miR-101, miR-124, miR-23b-3p, as well as miR-216b [135-138]. Autophagy and GAS5 expression were both decreased in breast cancer cells. Furthermore, the GAS5 expression levels in patient samples showed a negative correlation with tumor size, depth, TNM stage, as well as with poor clinical prognosis. Surprisingly, vector-induced GAS5 over-expression initiated autophagy, and also elevated p62, LC3, and ATG3 expression through sponging of miR-23a. This result could be helpful as a novel treatment for breast cancer via modulating the GAS5/miR-23a/ATG3 axis [139].

RNA editing involves discrete changes being made to specific nucleotide sequences within an existing RNA molecule. It has recently been shown that the process of A-to-I RNA editing can alter miRNA function [140]. For instance, compared to the wild-type miRNA, the edited miR-200b could increase the invasion and migration of cancer cells [141]. In another study, it was shown that the edited miR-379-5p, as opposed to the wild-type miR-379$5 p$ that targets CD97, suppressed rapid cell proliferation and increased apoptosis in tumor cells in-vitro [142]. Table 1 and Fig. 4 lists various autophagy-related miRNAs that have been reported to be involved in cancer.

\section{Autophagy and brain tumors: paving the way for the development of new drugs Alterations in autophagy in brain tumors}

The poor response of malignant brain tumors to conventional therapies, many of which work by inducing 
Table 1 Selected autophagy-associated miRNAs in cancer

\begin{tabular}{|c|c|c|c|c|c|}
\hline Cancer & MicroRNA & Target (s) & Effect (s) & Cell line (s) & Ref \\
\hline \multirow[t]{2}{*}{ Melanoma } & miR-290-295 & ATG7, ULK1 & Inhibit autophagy & R2L, B16F1 & [100] \\
\hline & miR-638 & TP53INP2 & Inhibit autophagy & SK-Mel-147, SK-Mel-28 & [143] \\
\hline \multirow[t]{2}{*}{ Esophageal cancer } & miR-193b & STMN1 & Activate autophagy & KYSE450 & [144] \\
\hline & miR-634 & BIRC5, XIAP, APIP, TFAM, OPA1, LAMP2 & Inhibit autophagy & KYSE850 & [145] \\
\hline \multirow[t]{4}{*}{ Squamous cell carcinoma } & miR-374a & ATG5, UVRAG & Inhibit autophagy & JHU-029 & [146] \\
\hline & miR-630 & UVRAG, ATG12 & Inhibit autophagy & JHU-029 & [146] \\
\hline & miR-519a & BECN1, ATG16L1, ATG10 & Inhibit autophagy & JHU-029 & [146] \\
\hline & miR-885-3p & AKT1, ULK2, ATG16L2, BCL-2 & Inhibit autophagy & JHU-029 & [147] \\
\hline \multirow[t]{7}{*}{ Colorectal cancer } & miR-18a & hnRNPA1 & - & HCT116, SW620 & [148] \\
\hline & miR-22 & BTG1 & Inhibit autophagy & RKO, SW620 & [149] \\
\hline & miR-93 & ATG16L1 & Inhibit autophagy & HCT116 & [150] \\
\hline & miR-106 & ATG16L1 & Inhibit autophagy & HCT116 & [150] \\
\hline & miR-183 & UVRAG & Inhibit autophagy & HT29, HCT116 & [151] \\
\hline & miR-409-3p & BECN1 & Inhibit autophagy & LovoOxa R & [152] \\
\hline & miR-502 & RAB1B & Inhibit autophagy & HCT116 & [153] \\
\hline \multirow[t]{2}{*}{ Gastric cancer } & miR-143 & GABARAPL1 & Inhibit autophagy & MKN28, AGS & [154] \\
\hline & miR-181a & ATG5 & Inhibit autophagy & SGC7901/CDDP & [155] \\
\hline \multirow[t]{9}{*}{ Lung cancer } & miR-7 & EGFR & Activate autophagy & A549, H1299 & [156] \\
\hline & miR-16 & $B C L-2$ & Inhibit autophagy & A549-T24 & [157] \\
\hline & miR-17-5p & BECN1 & Inhibit autophagy & A549-T24 & [105] \\
\hline & miR-143 & ATG2B & Inhibit autophagy & H1299 & [158] \\
\hline & miR-144 & TIGAR & Activate autophagy & $\mathrm{H} 460, \mathrm{~A} 549$ & [159] \\
\hline & miR-200b & ATG12 & Inhibit autophagy & H1299/DTX, SPC-A1/DTX & [160] \\
\hline & miR-216b & BECN1 & Inhibit autophagy & Calu-3, A549 & [161] \\
\hline & miR-451 & RAB14 & - & A549, NCl-H520, SPC-A1 & [162] \\
\hline & miR-487b-5p & LAMP2 & Inhibit autophagy & H1299, A549 & [163] \\
\hline \multirow[t]{7}{*}{ Breast cancer } & miR-25 & ULK1 & Inhibit autophagy & MCF-7 & [102] \\
\hline & miR-181a & ATG5 & Inhibit autophagy & MCF-7 & [119] \\
\hline & miR-199A-5p & BECN1, DRAM1 & Inhibit autophagy & MDA-MB-231, MCF-7 & [164] \\
\hline & miR-200c & UBQLN1 & Activate autophagy & MDA-MB-231 & [165] \\
\hline & miR-372 & SQSTM1 & Inhibit autophagy & MCF10A, MCF-7 & [166] \\
\hline & miR-376b & ATG4C, BECN1 & Inhibit autophagy & MCF-7 & [113] \\
\hline & miR-451a & - & Inhibit autophagy & LCC2, MCF-7 & [167] \\
\hline \multirow[t]{2}{*}{ Ovarian cancer } & miR-152 & ATG14 & Inhibit autophagy & SKOV3/DDP, A2780/CP70 & [168] \\
\hline & miR-373 & RAB22A & Inhibit autophagy & SKOV3 & [169] \\
\hline \multirow[t]{4}{*}{ Cervical cancer } & miR-15a/16 & RICTOR & Activate autophagy & HeLa & [170] \\
\hline & miR-20a & ATG7 & - & $\mathrm{SiHa}$ & [171] \\
\hline & miR-155 & RHEB, RPS6KB2, RICTOR & Activate autophagy & HeLa, NSE & [127] \\
\hline & miR-224-3p & FIP200 & Inhibit autophagy & SiHa, HeLa, C33A & [172] \\
\hline Endometrial carcinoma & miR-218 & HMGB1 & Inhibit autophagy & RL95-2 & [173] \\
\hline \multirow[t]{2}{*}{ Prostate cancer } & miR-96 & ATG7, mTOR & Inhibit autophagy & LAPC4, 22Rv1, LNCaP & [174] \\
\hline & miR-124 & PIM1 & Inhibit autophagy & PC3, DU145 & [175] \\
\hline \multirow[t]{2}{*}{ Liver cancer } & miR-21 & PTEN & Inhibit autophagy & HepG2, Huh7 & [176] \\
\hline & miR-101 & $\mathrm{EZH} 2$ & Inhibit autophagy & HepG2 & [177] \\
\hline
\end{tabular}


Table 1 Selected autophagy-associated miRNAs in cancer (Continued)

\begin{tabular}{|c|c|c|c|c|c|}
\hline Cancer & MicroRNA & Target (s) & Effect (s) & Cell line (s) & Ref \\
\hline & miR-199A-5p & ATG7 & Inhibit autophagy & HepG2, Huh7 & [178] \\
\hline & miR-224 & SMAD4 & Inhibit autophagy & Hbx, Нер3В & [179] \\
\hline & miR-375 & ATG7 & Inhibit autophagy & Hep3B, Huh7 & [114] \\
\hline & miR-376b & ATG4C, BECN1 & Inhibit autophagy & Huh7 & [113] \\
\hline \multirow[t]{2}{*}{ Pancreatic cancer } & miR-23a & ATG12 & Inhibit autophagy & $\mathrm{B} \times \mathrm{PC} 3$ & [180] \\
\hline & miR-216a & BECN1 & Inhibit autophagy & PANC-1 & [181] \\
\hline Kidney cancer & miR-214 & LC3B, LC3A & Inhibit autophagy & A498, 786-O, Caki-1 & [182] \\
\hline Thyroid cancer & miR-9-3p & ATG5 & Inhibit autophagy & MZ-CRC-1, TT & [183] \\
\hline \multirow[t]{3}{*}{ Hepatocellular carcinoma } & miR-17 & PTENP1, PTEN & Activate autophagy & Mahlavu & [184] \\
\hline & miR-19b & PTENP1, PTEN & Activate autophagy & Mahlavu & [184] \\
\hline & miR-20a & PTENP1, PTEN & Activate autophagy & Mahlavu & [184] \\
\hline
\end{tabular}

apoptosis, makes it attractive to target autophagy as an alternative mechanism for triggering glioma cell death $[185,186]$. Alterations or mutations that are commonly found in brain tumors, include p53, PTEN, AKT, NF1 and EGFR, and some of these are accepted to be implicated in the modulation of autophagy $[185,186]$. Considering the frequencies of mutations in EGFR, p53,
PTEN, NF1, and PDGFR, the Cancer Genome Atlas consortium categorized glioblastoma (GBM) tumors into four molecular sub-types, including neural, classical, mesenchymal, and proneural [187]. Researchers have also found differences in basal expression levels of the LC3 protein in xenografts of the GBM four subtypes, which were associated with differences in the

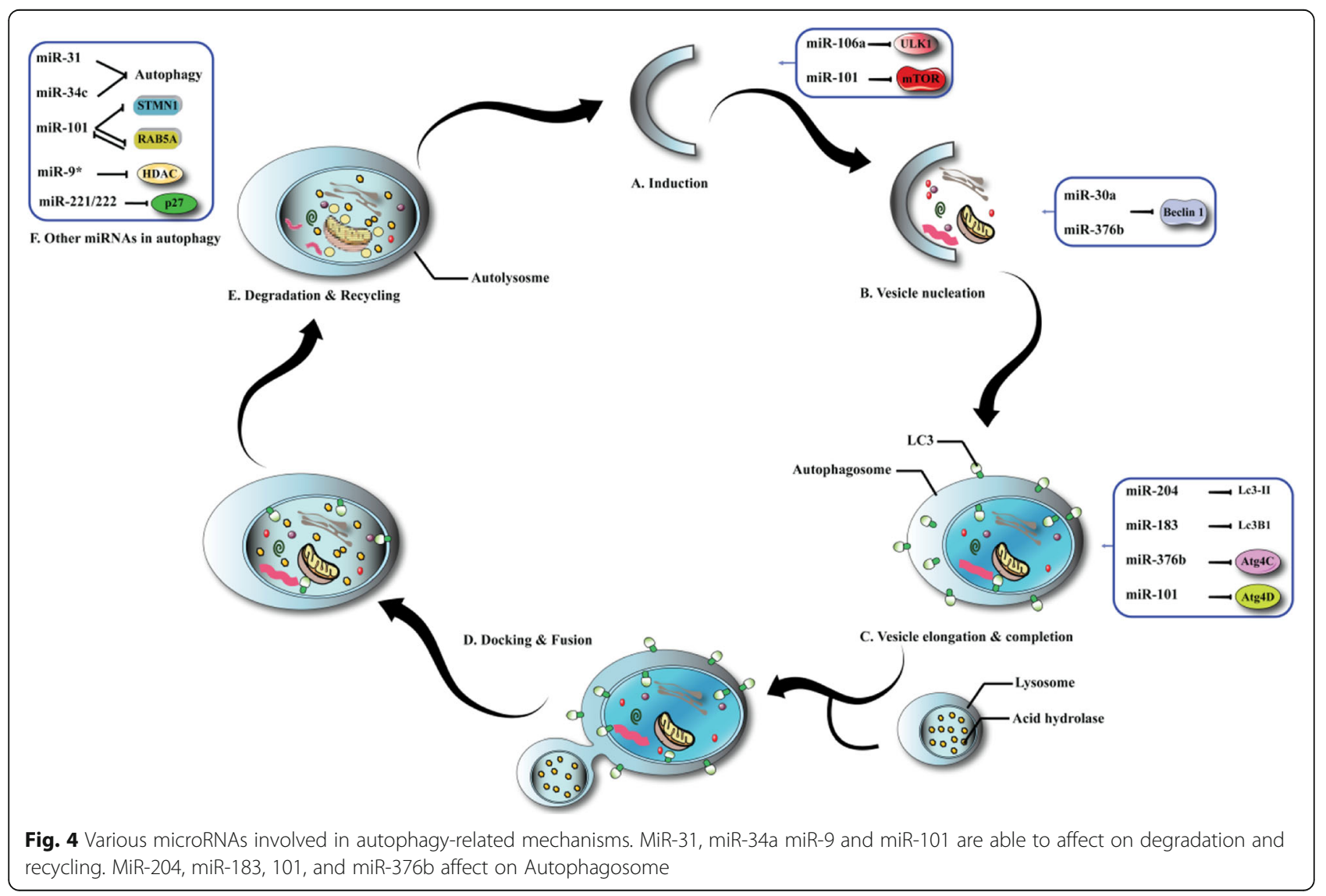


susceptibility to autophagy. It has been proposed that combinational approaches targeting autophagylysosomal related mechanisms might result in improved GBM subtype-specific treatments. Furthermore, it has been shown that autophagy can be activated by some experimental glioma treatments. Although autophagy can increase the survival and resistance of tumor cells under some circumstances, autophagy is also able to exert cytostatic and/or cytotoxic effects in other therapeutic approaches. The particular role of autophagy in contributing to cell death or cell survival in different therapeutic approaches is yet to be fully explained, and a better understanding of these contrary findings is essential to design potential combination therapies [187].

The most frequent genetic alterations/mutations found in gliomas are: hemizygous/homozygous deletion of NF1 and PTEN; EGFR vIII mutant expression; and EGFR amplification [187]. The abnormal signaling resulting from such mutations interacts with PI3K-Akt-mTOR pathways that promotes chemo-resistance and survival in gliomas [188]. Thus, the idea to target receptor tyrosine kinases (RTKs) using small molecule inhibitors, or else with monoclonal antibodies has emerged as a favored therapeutic approach (Fig. 5).

\section{Development of therapeutic drugs}

Disappointingly, the first clinical trials that were conducted with small molecule EGFR inhibitors, including gefitinib and erlotinib that had shown success for other tumor types, did not show any encouraging results for glioma treatment [189-191]. Likewise, monoclonal antibodies targeting EGFR (panitumumab and cetuximab) only exerted cytostatic effects on glioma cell lines [192, 193]. However, the variety of different types of RTK that are found in gliomas (combined with frequency of PTEN elimination) could explain the ineffectiveness of tyrosine kinase inhibitors (TKI) each of which only targets a single enzyme [194-196]. Moreover, preclinical investigations using selected mTOR and PI3K inhibitors, have shown only a moderate efficacy against gliomas. A phase-II trial using temsirolimus (CCI-779), a mTOR blocker, did not improve survival in patients with recurrent GBM [197]. However, PI-103, a dual functional mTOR and PI3K inhibitor, did show beneficial antiproliferative effects in preclinical glioma models, by suppressing the Akt activation often found with mTOR blockers [198]. Treatments which targeted components of the RTK-PI3K-Akt-mTOR axis, increased the induction of autophagy with an overall cytoprotective effect. Therefore, a combination of inhibitors of late stage autophagy plus other compounds that actually induce autophagy may work together to increase the cytotoxicity in gliomas. Indeed, this concept was tested in one approach, which combined the lysosomotrophic agent chloroquine (CQ) that blocked the activity of lysosomal proteases, with the PI3K/mTOR/AKT inhibitors (AKT$1 / 2$ and PI-103), resulting in the overall potentiation of glioma cell death [199]. Furthermore, NVP-BEZ235 (a dual mTOR and PI3K inhibitor currently being tested in clinical trials) induced autophagy in solid tumors, and synergistically acted in combination with $\mathrm{CQ}$ through increased apoptosis in glioma cells [200]. A combination of monensin or bafilomycin A1 (both late-stage autophagy inhibitors) with $\mathrm{Ku}-0063794$ or PI-103 also promoted glioma cell death via apoptosis induction [200]. Also, experts in the field have proposed that inhibition of autophagy could act synergistically with erlotinib for induction of cytotoxicity in GBM cells [201]. In the case of a combination of autophagy inhibitors with the TKI, imatinib mesylate, the precise stage at which autophagy was suppressed led to different outcomes in gliomas. Early-stage inhibition of autophagy using small interfering RNAs targeting ATG5 or 3-methyladenine (3-MA) decreased imatinib cytotoxicity, whereas conversely suppression of late-phase autophagy using bafilomycin A1 increased cytotoxicity by inducing more apoptosis [202]. Therefore, the varying outcomes of autophagy suppression under different conditions may depend on the specific compound that targets different stages of autophagy, and on other factors that are not yet completely understood.

Although the combination of drugs which induce autophagy, with agents that inhibit the completion of autophagy, appear to be somewhat promising up to now, and some clinical trials are actually in progress, there are other treatments that can contribute to autophagy-associated glioma cell death. For example, adding an inducer of autophagy, to some common chemotherapeutic drug regimens could increase cytotoxicity.

Several agents can cause autophagic cell death in different kinds of cancer, such as IFN- $\gamma$, resveratrol, vitamin $\mathrm{D}$ analogues, tamoxifen, arsenic trioxide, and actinomycin D. In glioma cell lines, it has been shown that arsenic trioxide can induce autophagy-related cell death by up-regulation of BNIP3 (a member of the Bcl-2 family), as well as its respective homologue BNIP3L. According to earlier findings, displacement of Beclin1 from its complex with Bcl-2 (BNIP3) enhances autophagy. Furthermore, BNIP3 over-expression also induced autophagy in some cell types [203]. Likewise, BNIP3 can make a key contribution to ceramide-mediated autophagy in malignant glioma cells [204]. An inorganic compound, sodium selenite, was also able to induce autophagy in malignant glioma cells via superoxideinduced mitochondrial damage [205]. Sodium selenite, ceramide and arsenic trioxide have all been shown to 


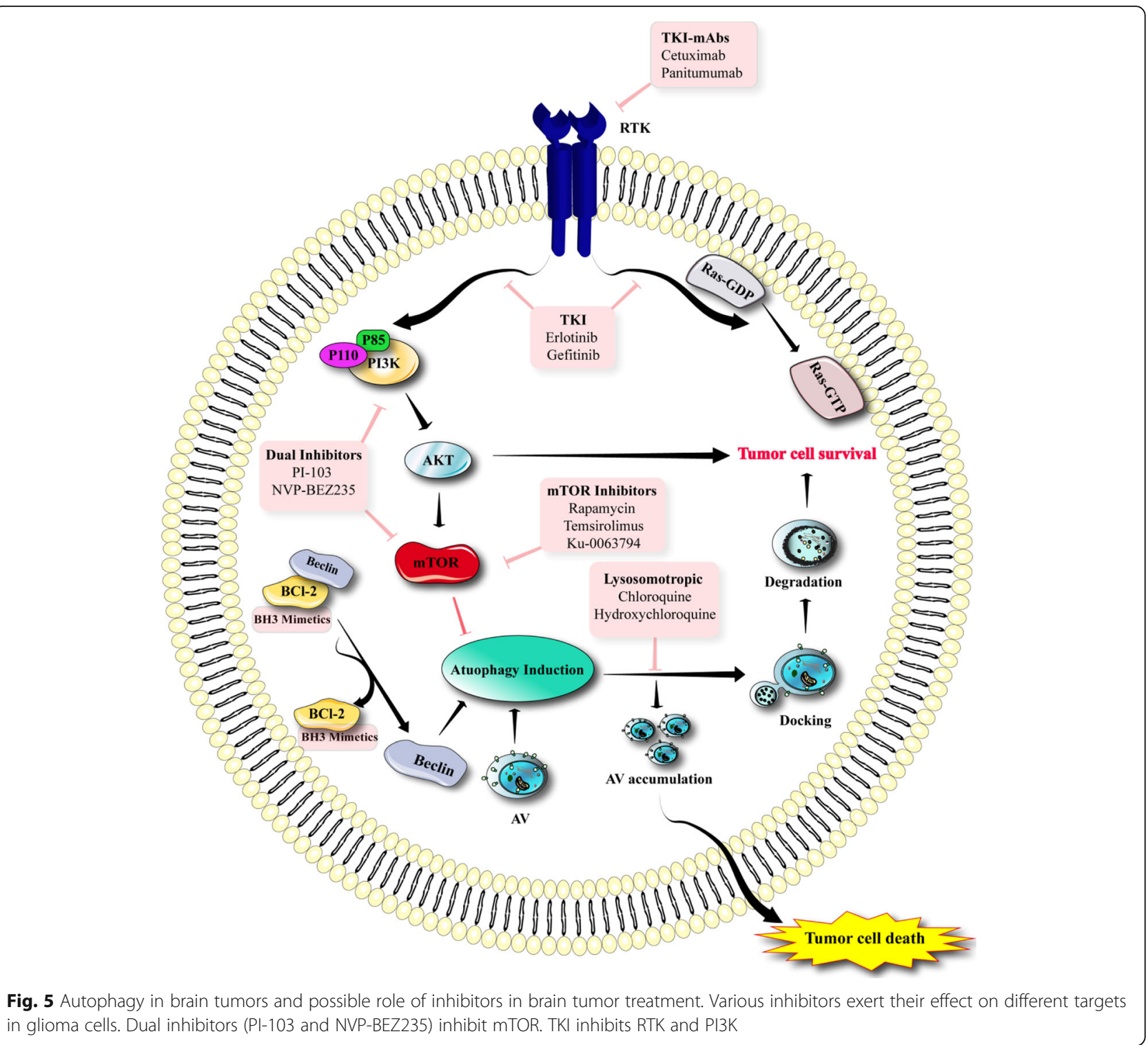

contribute to autophagic cell death by triggering mitochondrial damage. However, $\Delta^{9}$-tetrahydrocannabinol (THC) resulted in autophagy-related glioma cell death through induction of ER stress [206].

GBMs contain many hypoxic regions, and there can also be large necrotic regions inside the tumors. Increased expression levels of Bcl-2 family members leads to resistance to hypoxia in gliomas [207], and may result in increased resistance to some therapies. BH3 mimetics are small molecules, which can selectively attach to the $\mathrm{BH} 3$-binding groove of the anti-apoptotic $\mathrm{Bcl}-2$ proteins. Therefore, $\mathrm{BH} 3$ mimetics are able to disturb the interaction between Bcl-2/beclin1 as well as between Bax/ $\mathrm{Bcl}-2$, in order to trigger autophagy or apoptosis in different kinds of cancer. In hypoxia-resistant malignant glioma cells, it was found that BH3 mimetics could induce autophagy-dependent cell death [207]. In addition, gossypol (a BH3 mimetic) specifically induces caspaseindependent autophagic cell death [208].

p53 has been shown to be mutated in about one third of gliomas, and it can reduce the susceptibility of tumors to treatments that induce apoptosis [209]. Investigators have found that autophagy-related cell death can be induced in gliomas by addition of $C Q$, independently of the p53 status [210]. Nevertheless, p53 plays an essential role in governing autophagy in a variety of therapeutic approaches. Autophagy and DNA damage have both been induced by selective inhibitors of cyclooxygenase-2 (e.g. celecoxib) in glioma cells, which require a functional p53 pathway [211]. 


\section{MicroRNAs and autophagy in brain tumors}

GBM is the most common as well as the most lethal primary tumor in the CNS [212, 213]. Nonetheless, all GBMs are not uniform and can display fundamental heterogeneity and may contain small sub-populations of cells, that have been called "glioma stem-like cells" (GSCs). One study suggested that GSCs are mainly responsible for tumor initiation, specify the malignant phenotype, cause therapy-resistance, and recurrence [214]. Analysis of gene expression has categorized GSCs extracted from patients into sub-types: mesenchymal (MES); classical (CL); and proneural (PN) [215-217]. Among them, MES GSCs have been suggested to be the most radiation-resistant and invasive cells [217]. The enhanced autophagic activities in the MES GSCs as compared to the PN GSCs, has been implicated in the high tumorigenicity and resistance to therapy [218].

MiR-93 is an important miRNA, which is highly expressed in different human cancers, and functions as one of the oncogenic miRNAs, through actuation of PI3K-AKT signaling pathways [219, 220]. Nevertheless, oncogenic effects of miR-93 has been considered to be depended on the contexts. As an instace, miR-93 acts as one of the tumour suppressors via suppressing parameters in a TGF- $\beta$ signaling pathway, and the genes responsible for cell stemness such as EZH1, SOX4, AKT3, STAT3, JAK1, CDKN1A, and CCND2 [221, 222].

Huang and colleagues examined two clinically relevant GBM subtypes, and found that miR-93 expression affected the GSC phenotype, together with the response to therapy, due to its effects on autophagy [223]. They also showed that miR-93 modulated autophagy functions in GSCs by synchronized suppression of several autophagy modulators, such as SQSTM1/p62, ATG4B, ATG5 and BECN1/beclin 1. Furthermore, two first-line GBM therapies, Temozolomide (TMZ) and irradiation (IR), as well as rapamycin (Rap) decreased the expression of miR-93, which itself, triggered the autophagic cascades in the GSCs. In fact, autophagy suppression using the ectopic expression of miR-93, or mediated by autophagy blockers, CQ and NSC (the ATG4B suppressor), increased TMZ as well as IR activities against the GSCs. The results suggested an important role for miR-93 in autophagy regulation, and proposed a combination therapeutic approach using autophagy suppression while administering cytotoxic treatment [223].

It has been shown that miR-30a has suppressive effects on autophagy, through direct targeting of beclin1 [224]. $\mathrm{Xu}$ and colleagues studied whether miR-30a enhanced TMZ cytotoxicity against GBMU251 cells, and the underlying mechanisms [225]. They found that TMZ therapy blocked the proliferation of U251 cells, while inducing apoptosis in a dose-dependent manner. Moreover, beclin1 and LC3-II expression levels, as well as the
LC3-II to LC3-I ratio were significantly enhanced in TMZ-treated U251 cells in comparison to untreated cells. These results suggested that TMZ therapy could induce autophagy. Researchers found that TMZ therapy resulted in a considerable reduction of miR-30a expression levels in U251 cells in a dose-dependent manner. MiR-30a significantly suppressed autophagy induced by TMZ, as confirmed by the reduced levels of beclin 1 and LC3-II, as well as lower ratio of LC3-II to the LC3-I, accompanied by elevated apoptosis as well as decreased proliferation of TMZ-treated U251 cells. Overall, this study showed that, miR-30a enhanced the TMZ chemosensitivity of GBMU251 cells through direct suppression of autophagy. Consequently, autophagy may be a target for improving the treatment effects against TMZresistant tumors [225].

Flavonoids (phenolic compounds derived from plants) have a wide range of pharmacological properties including antitumor activity. Studies have recently revealed the ability of flavonoids to affect cancer cell metastasis, angiogenesis, differentiation, proliferation, apoptosis, and multi-drug resistance [226]. The anticancer impact of luteolin (LUT), a naturally occurring flavonoid, includes suppression of metastasis, angiogenesis, cell proliferation and autophagy, as well as stimulation of apoptotic pathways [227]. During the passage through the intestinal mucosa, some LUT molecules are probably converted to glucuronides [228]. Due to its ability to cross the bloodbrain barrier, LUT could be considered an appropriate molecule for the treatment of different brain tumors, such as GBM [229].

Ray and Chakrabarti showed that a combination of $50 \mu \mathrm{M}$ SIL (silibilin, a flavonolignan) and $20 \mu \mathrm{M}$ LUT synergistically inhibited the growth of T98G and GBMU87MG cells, and the combination of these two natural compounds was more effective than conventional chemotherapy $(100 \mu \mathrm{M}$ TMZ or $10 \mu \mathrm{M}$ BCNU) [230]. The SIL and LUT combination suppressed GBM cell growth via inducing apoptosis and inhibiting tumor cell migration and invasion. Additionally, the SIL and LUT combination repressed rapamycin (RAPA)-mediated autophagy by PKC $\alpha$ suppression, and promoted apoptosis through iNOS down-regulation. The combination also significantly enhanced the expression of the tumor inhibitor miR-7-1-3p in GBM cells. It was also shown that miR-7-1-3p over-expression increased the antitumor activity of SIL and LUT in RAPA-pre-treated T98G and U87MG cells. Consequently, these findings indicated that miR-7-1-3p over-expression enhanced the antitumor effects of SIL and LUT to induce apoptosis and suppress autophagy in several human GBM-cells, both in-vivo and in-vitro [230].

Under hypoxic conditions, autophagy can have a protective effect on cancer cells. Moreover, hypoxia affects 
Table 2 Selected autophagy-related miRNAs in brain tumors

\begin{tabular}{|c|c|c|c|c|c|c|c|c|}
\hline Brain tumor & miRNA & Expression & $\begin{array}{l}\text { Effect (s) } \\
\text { on } \\
\text { autophagy }\end{array}$ & Target (s) & Study outcome (s) & Model & Cell line & Ref \\
\hline \multirow[t]{13}{*}{ GBM } & $\begin{array}{l}\text { miR- } \\
93\end{array}$ & Up & $\begin{array}{l}\text { Inhibit } \\
\text { autophagy }\end{array}$ & $\begin{array}{l}\text { BECN1/ } \\
\text { Beclin 1, } \\
\text { ATG5, } \\
\text { ATG4B, } \\
\text { SQSTM1/p62 }\end{array}$ & $\begin{array}{l}\text { Autophagy inhibition increased antitumor } \\
\text { effects of Rap, IR, and TMZ on glioma stem- } \\
\text { like cells }\end{array}$ & $\begin{array}{l}\text { In } \\
\text { vitro, } \\
\text { In vivo }\end{array}$ & U87 & [237] \\
\hline & $\begin{array}{l}\text { miR- } \\
30 a\end{array}$ & Up & $\begin{array}{l}\text { Inhibit } \\
\text { autophagy }\end{array}$ & Beclin 1 & $\begin{array}{l}\text { MiR-30a over-expression increased the cyto- } \\
\text { toxicity of TMZ to U251 cells }\end{array}$ & $\begin{array}{l}\text { In } \\
\text { vitro }\end{array}$ & U251 & [225] \\
\hline & $\begin{array}{l}\operatorname{miR}- \\
224- \\
3 p\end{array}$ & Up & $\begin{array}{l}\text { Inhibit } \\
\text { autophagy }\end{array}$ & ATG5 & $\begin{array}{l}\text { Mir-224-3p suppressed metastasis. It also } \\
\text { enhanced the chemo-sensitivity of LN229 } \\
\text { cells in hypoxic conditions through autoph- } \\
\text { agy suppression }\end{array}$ & $\begin{array}{l}\text { In } \\
\text { vitro, } \\
\text { In vivo }\end{array}$ & LN229 & [238] \\
\hline & $\begin{array}{l}\text { miR- } \\
17\end{array}$ & Up & $\begin{array}{l}\text { Inhibit } \\
\text { autophagy }\end{array}$ & ATG7 & $\begin{array}{l}\text { The activation of autophagy by anti-miR-17 } \\
\text { led to a decrease of the threshold resistance } \\
\text { at temozolomide doses in T98G cells. } \\
\text { Modulation of miR-17 led to sensitization to } \\
\text { low dose ionizing radiation in U373-MG cells }\end{array}$ & $\begin{array}{l}\text { In } \\
\text { vitro }\end{array}$ & T98G, U373-MG & [115] \\
\hline & $\begin{array}{l}\text { miR- } \\
340\end{array}$ & Up & $\begin{array}{l}\text { Inhibit } \\
\text { autophagy }\end{array}$ & $\begin{array}{l}\text { XIAP, BMI1, } \\
\text { ROCK1 }\end{array}$ & $\begin{array}{l}\text { MiR-340 reduced cell growth, inhibited cell } \\
\text { motility, and regulated glioma development }\end{array}$ & $\begin{array}{l}\text { In } \\
\text { vitro }\end{array}$ & $\begin{array}{l}\text { U87MG, U251MG, } \\
\text { U373, A172, U118, } \\
\text { T98G, SHU-44 }\end{array}$ & [239] \\
\hline & $\begin{array}{l}\text { miR- } \\
224- \\
3 p\end{array}$ & Up & $\begin{array}{l}\text { Inhibit } \\
\text { autophagy }\end{array}$ & ATG5, FIP200 & $\begin{array}{l}\text { MiR224-3p increased hypoxia-induced apop- } \\
\text { tosis, inhibited hypoxia-induced autophagy, } \\
\text { reduced cell proliferation in vitro, inhibited } \\
\text { tumorigenesis of GBM cells in vivo }\end{array}$ & $\begin{array}{l}\text { In } \\
\text { vitro, } \\
\text { In vivo }\end{array}$ & U251, U87 & [232] \\
\hline & $\begin{array}{l}\text { miR- } \\
517 \mathrm{c}\end{array}$ & Up & $\begin{array}{l}\text { Inhibit } \\
\text { autophagy }\end{array}$ & Tp53 & $\begin{array}{l}\text { Mir-517c suppressed autophagy and } \\
\text { decreased tumor invasion }\end{array}$ & $\begin{array}{l}\text { In } \\
\text { vitro, } \\
\text { In vivo }\end{array}$ & U251, U87 & [240] \\
\hline & $\begin{array}{l}\text { miR-7- } \\
1-3 p\end{array}$ & Up & $\begin{array}{l}\text { Inhibit } \\
\text { autophagy }\end{array}$ & $\begin{array}{l}\text { PKCa, mTOR, } \\
\text { SQSTM1, } \\
\text { P62, XIAP }\end{array}$ & $\begin{array}{l}\text { MiR-7-1-3p over-expression potentiated sili- } \\
\text { binin \& luteolin to induce apoptosis and in- } \\
\text { hibit autophagy }\end{array}$ & $\begin{array}{l}\text { In } \\
\text { vitro, } \\
\text { in vivo }\end{array}$ & U87MG, T98G & [230] \\
\hline & $\begin{array}{l}\operatorname{miR}- \\
138\end{array}$ & Up & $\begin{array}{l}\text { Inhibit } \\
\text { autophagy }\end{array}$ & LC3-II, BIM & $\begin{array}{l}\text { MiR-138/BIM axis regulated autophagy- } \\
\text { mediated resistance to TMZ }\end{array}$ & $\begin{array}{l}\text { In } \\
\text { vitro, } \\
\text { In vivo }\end{array}$ & $\begin{array}{l}\text { LN-18, LN-229, LN- } \\
308, \text { LN-319, LN-428, } \\
\text { D247MG, A172, } \\
\text { U87MG, T98G }\end{array}$ & [241] \\
\hline & $\begin{array}{l}\text { miR- } \\
155- \\
3 p\end{array}$ & Up & $\begin{array}{l}\text { Activate } \\
\text { autophagy }\end{array}$ & $\begin{array}{l}\text { LC3B-II, } \\
\text { SQSTM1 }\end{array}$ & $\begin{array}{l}\text { MIR155-3p enhanced hypoxia-induced au- } \\
\text { tophagy through targeting the CREBRF- } \\
\text { CREB3-ATG5 pathways }\end{array}$ & $\begin{array}{l}\text { In } \\
\text { vitro, } \\
\text { In vivo }\end{array}$ & U251, T98G & [242] \\
\hline & $\begin{array}{l}\text { miR- } \\
30 e\end{array}$ & Up & $\begin{array}{l}\text { Inhibit } \\
\text { autophagy }\end{array}$ & Beclin-1 & $\begin{array}{l}\text { Combination of proanthocyanidin and miR- } \\
\text { 30e suppressed sodium sulfite-induced } \\
\text { autophagy }\end{array}$ & $\begin{array}{l}\text { In } \\
\text { vitro }\end{array}$ & GSC, SNB19 & [243] \\
\hline & $\begin{array}{l}\operatorname{miR}- \\
128\end{array}$ & Up & $\begin{array}{l}\text { Activate } \\
\text { autophagy }\end{array}$ & $\begin{array}{l}\text { mTOR, } \\
\text { RICTOR, } \\
\text { IGF1, PIK3R1 }\end{array}$ & $\begin{array}{l}\text { MiR-128 directly blocked mTOR pathway } \\
\text { and induced glioma cell death }\end{array}$ & $\begin{array}{l}\text { In } \\
\text { vitro }\end{array}$ & $\begin{array}{l}\text { Hs683, M059K, } \\
\text { U87MG }\end{array}$ & [244] \\
\hline & $\begin{array}{l}\text { miR- } \\
590- \\
3 p\end{array}$ & Up & $\begin{array}{l}\text { Activate } \\
\text { autophagy }\end{array}$ & $\begin{array}{l}\text { LC3-II, } \\
\text { Beclin-1, }\end{array}$ & $\begin{array}{l}\text { TMZ combined with endothelial-monocyte } \\
\text { actuating polypeptide II inhibited malignant } \\
\text { phenotype of GSCs through miR-590-3p/ } \\
\text { MACC1 suppressing the PI3KJAKT/mTOR sig- } \\
\text { naling pathways }\end{array}$ & $\begin{array}{l}\text { In } \\
\text { vitro, } \\
\text { In vivo }\end{array}$ & U87, U251 & [245] \\
\hline \multirow[t]{2}{*}{ Scwannoma } & $\begin{array}{l}\operatorname{miR}- \\
21\end{array}$ & Up & $\begin{array}{l}\text { Inhibit } \\
\text { autophagy }\end{array}$ & $\begin{array}{l}\text { LC3-II, } \\
\text { Beclin-1 }\end{array}$ & $\begin{array}{l}\text { Ailanthone-induced autophagy \& apoptosis, } \\
\text { suppressed proliferation of vestibular } \\
\text { schwannoma cells }\end{array}$ & $\begin{array}{l}\text { In } \\
\text { vitro }\end{array}$ & $\begin{array}{l}\text { vestibular } \\
\text { schwannoma }\end{array}$ & {$[234]$} \\
\hline & $\begin{array}{l}\operatorname{miR}- \\
210\end{array}$ & Up & $\begin{array}{l}\text { Activate } \\
\text { autophagy }\end{array}$ & P62, elf4E & $\begin{array}{l}\text { Inhibition of miR-210 promoted tumor cell } \\
\text { apoptosis and cell cycle arrest, decreased } \\
\text { angiogenesis, and activated autophagy }\end{array}$ & $\begin{array}{l}\text { In } \\
\text { vitro }\end{array}$ & RT4-D6P2T & [246] \\
\hline \multirow[t]{2}{*}{ Medulloblastoma } & $\begin{array}{l}\text { miR- } \\
30 a\end{array}$ & Up & $\begin{array}{l}\text { Inhibit } \\
\text { autophagy }\end{array}$ & $\begin{array}{l}\text { LC3B, Beclin- } \\
1\end{array}$ & $\begin{array}{l}\text { Mir-30a inhibited tumorigenicity and growth } \\
\text { of medulloblastoma cell lines, and } \\
\text { suppressed autophagy }\end{array}$ & $\begin{array}{l}\text { In } \\
\text { vitro, } \\
\text { In vivo }\end{array}$ & Daoy, D283, D425 & [236] \\
\hline & Let-7f- & Up & Inhibit & HMGB1 & SPARC regulated cisplatin resistance by & $\ln$ & D425 & [247] \\
\hline
\end{tabular}


Table 2 Selected autophagy-related miRNAs in brain tumors (Continued)

\begin{tabular}{|c|c|c|c|c|c|c|c|c|}
\hline Brain tumor & miRNA & Expression & $\begin{array}{l}\text { Effect (s) } \\
\text { on } \\
\text { autophagy }\end{array}$ & Target (s) & Study outcome (s) & Model & Cell line & Ref \\
\hline & 1 & & autophagy & & regulating the Let-7f-1 miRNA/HMGB1 axis & $\begin{array}{l}\text { vitro, } \\
\text { In vivo }\end{array}$ & UW228 & \\
\hline Glioma & $\begin{array}{l}\text { miR- } \\
193 a- \\
5 p\end{array}$ & Up & $\begin{array}{l}\text { Activate } \\
\text { autophagy }\end{array}$ & $\begin{array}{l}\text { LCII/LCl, } \\
\text { Beclin-1 }\end{array}$ & $\begin{array}{l}\text { CASC2 is down-regulated in glioma, leading } \\
\text { to enhanced levels of miR-193a-5p and de- } \\
\text { creased expression of mTOR, resulting in in- } \\
\text { creased autophagy }\end{array}$ & $\begin{array}{l}\text { In } \\
\text { vitro }\end{array}$ & U257, U87 & [248] \\
\hline Astrocytoma & $\begin{array}{l}\text { miR- } \\
224- \\
3 p\end{array}$ & Up & $\begin{array}{l}\text { Inhibit } \\
\text { autophagy }\end{array}$ & ATG5 & $\begin{array}{l}\text { HIF-1a/miR-224-3p/ATG5 axis influenced } \\
\text { chemosensitivity and cell mobility through } \\
\text { modulating hypoxia-mediated autophagy }\end{array}$ & $\begin{array}{l}\text { In } \\
\text { vitro, } \\
\text { In vivo }\end{array}$ & U-251MG & [245] \\
\hline
\end{tabular}

protein stability, mRNA stability, and also mRNA transcription. In addition, hypoxia causes a shift in expression levels of a particular class of miRNAs [231]. The mechanisms of miRNA-associated hypoxia-induced autophagy in GBM are not yet fully understood. A study using miRNA microarray analysis in GBM cells, revealed the differential expression of several miRNAs under hypoxic condition [232]. It has also been reported that miR224-3p could be implicated in the regulation of hypoxia-mediated autophagy in GBM cells. The overexpression of miR224-3p inhibited hypoxia-induced autophagy, while its down-regulation promoted autophagy under normoxic conditions. Moreover, one study [232] reported that miR224-3p directly suppressed the expression of two autophagy-associated genes i.e., ATG5 \& FAK family interacting protein of $200 \mathrm{kDa}$ (FIP200) and therefore inhibited autophagy. Furthermore, miR224-3p enhanced hypoxia-induced apoptosis and decreased cell proliferation in vitro, and its over-expression inhibited GBM tumorigenesis in vivo. These authors demonstrated that miR224-3p is a new down-regulated miRNA in hypoxia, and could be a significant autophagy regulator by suppression of ATGs in GBM cells.

Vestibular schwannoma (VS) is a Schwann cell tumor of the vestibular nerves, and comprises about $10 \%$ of intracranial neoplasms [233]. VS occurs in both familial (neurofibromatosis type 2, NF2) and sporadic forms, both of which are related to defects in the NF2 gene [233]. In one investigation, the antitumor effects of ailanthone (AIL) (a quassinoid compound derived from the traditional Chinese medicinal herb, Ailanthus altissima) against VS was evaluated by Yang and colleagues [234]. Different doses of AIL $(0-1 \mu \mathrm{M})$ were used to treat VS cells, and autophagy, apoptosis, cell viability and proliferation were evaluated. After miRNA transfection, miR-21 expression was increased in VS cells. AIL significantly decreased VS cell viability. In response to $0.6 \mu \mathrm{M}$ AIL, p62 was down-regulated, beclin-1 and LC3II were accumulated, caspase 3 and caspase- 9 were cleaved, the rate of apoptotic cells was increased, and the expression of cyclin D1 as well as the proportion of
$\mathrm{BrdU}^{+}$cells were decreased. miR-21 was poorly expressed in cells treated with AIL, and furthermore AIL-mediated autophagy and apoptosis were reduced by the over-expression of miR-21. Furthermore, AIL downregulated Raf and Ras, and also deactivated p70S6K, mTOR, ERK and MEK, whereas the deactivation and down-regulation of these mediators induced by AIL were reversed by miR-21 over-expression. Consequently, AIL suppressed the proliferation of VS cells and induced autophagy and apoptosis. The anticancer properties of AIL in VS cells were explained by miR-21 downregulation and consequent suppression of the mTOR and Ras/Raf/MEK/ERK pathways [234].

Approximately, 30\% of patients with medulloblastoma, another malignant pediatric brain tumor [235], undergo metastasis at an early stage, and therefore they have a poor prognosis. If harsh cytotoxic therapy is administered to children whose brain is still developing, the surviving patients can suffer long-lasting developmental, endocrine and neurocognitive deficits. Therefore, in order to achieve a more effective treatment for medulloblastoma with fewer side effects, it is essential to discover more targeted therapeutic approaches based on validated biological mechanisms. It is believed that, because the SHH and WNT developmental pathways are involved, medulloblastoma could result from the deregulated expansion of cells in the nervous system [235]. Moreover, one study carried out by Singh et al. found low expression levels of miR-30a (which targets beclin1) in the medulloblastoma cell lines, D425, D283, and Daoy. Restoring the miR-30a expression level blocked tumorigenicity, and reduced the clonogenic potential as well as the proliferation of the medulloblastoma cells. It was proposed that miR-30a down-regulates the expression of beclin1, and suppresses autophagy in medulloblastoma cell-lines, by LC3B down-regulation. This could be reversed by CQ therapy, which induces starvation-induced autophagy. Therefore, miR-30a could be considered as a treatment approach for medulloblastoma, via suppressing autophagy, reversing the malignant phenotype, and reducing survival of cancer cells [236]. 
Table 2 lists some of the various miRNAs that have been associated with autophagy in brain tumors.

\section{Conclusion}

Due to the generally poor survival of patients diagnosed with malignant brain tumors (especially GBM), it is necessary to discover novel therapeutic strategies with fewer side effects. According to mounting evidence, disturbed autophagy critically contributes to the pathogenesis as well as progression of brain tumors. Therefore, new rationally designed drugs are needed, that should be soundly based on the underlying mechanisms of autophagy. Recent data shows that miRNAs can regulate and influence autophagy through different pathways. Therefore, miRNAs such as miR-30a, could be considered as a new therapeutic approach for the therapy of brain tumors, via suppressing autophagy, which has been shown to play a role on the malignant phenotype, survival and growth of cancer cells. The present review has summarized studies related to this concept, but it is obvious that there is still a long way to go before miRNA-based drugs could be used for brain tumor treatment. In order to find novel potential drugs for brain tumors, further attention should be focused on the regulatory properties of different miRNAs in the autophagy cascade. To reach this goal, more experimental studies must be conducted to clarify the underlying molecular mechanisms, and then clinical trials could be warranted to prove the effectiveness and safety of therapies based on miRNAs.

\footnotetext{
Abbreviations

AGO: Argonaute; ATG: Autophagy-related gene; AMAPK: AMP-activated protein kinase; BECN1: Beclin 1; BNIP3: BCl-2 nineteen-kilodalton interacting protein 3; CAMKK2: Calcium/calmodulin-dependent protein kinase kinase 2; CDKN1A: Cyclin Dependent Kinase Inhibitor 1A; CCND2: Cyclin D2; CL: Classical; CNS: Nervous system; CSF: Cerebrospinal fluid; DRAM2: DNA damage-regulated autophagy modulator 2; CQ: Chloroquine; EGFR: Epidermal growth factor receptor; ERK: Extracellular Signal-regulated Kinase; EXH1: Enhancer of zeste homolog 1; GBM: Glioblastoma; HCC: GABARAPL1: GABA Type A Receptor Associated Protein Like 1; Hepatocellular carcinoma; LAMP-1: Lysosomal-associated membrane protein 1; LC3: Light chain 3; LncRNA: Long non-coding RNA; LUT: Luteolin; MEFs: Mouse embryonic fibroblasts; MEK: Mitogen-activated protein kinase; MES: Mesenchymal; MREs: miRNA response elements; mTORC1: Mammalian target of rapamycin complex 1; NF1: Neurofibromatosis type l; HOPS: Homotypic fusion and protein sorting-tethering complex; PKM1: Pyruvate kinase isozymes M1; PTB1: Polypyrimidine tract-binding protein 1; PE: Phosphatidylethanolamine; PDGFR: Platelet-derived growth factor receptors; PI3K: Phosphatidylinositol 3kinase; PIK3C3: Phosphatidylinositol 3-Kinase Catalytic Subunit Type 3; PML: Promyelocytic leukemia; PN: Proneural; PHLPP: PH domain and leucine rich repeat protein phosphatase 1; PTEN: Phosphatase and tensin homolog; RCC: Renal clear cell carcinoma; RISC: RNA-induced silencing complex; RAB1B: Ras-related protein Rab-1B; TTKs: Receptor tyrosine kinases; RUNX3: Runt-related transcription factor 3; SQSTM1: Sequestosome-1; SIRT1: Silent mating type information regulation 2 homolog 1; SNAREs: Soluble N-ethylmaleimide-sensitive agent attachment protein receptors; SNAP29: Synaptosomal-associated protein 29; STX17: Syntaxin 17; STAT3: Signal transducer and activator of transcription 3; TIGAR: TP53inducible glycolysis and apoptosis regulator; TKl: Tyrosine kinase inhibitors; THC: Tetrahydrocannabinol; TRPM3: Transient receptor potential melastatin 3; VAMP8: Vesicle-associated membrane protein 8; VHL: Von Hippel-Lindau;
}

VPS34: Vacuolar protein sorting 3; VS: Vestibular schwannoma; ULK: Unc-51like kinase; YY1: Yin Yang 1a

\section{Acknowledgements \\ Not applicable.}

\section{Authors' contributions}

$\mathrm{HM}$ and $\mathrm{MRH}$ contributed to the conception, design, statistical analysis and drafting of the manuscript. MH-P, MRK, MM-T, HRM, ZSR, and AS contributed to data collection and manuscript drafting. All authors approved the final version for submission.

Funding

MRH was supported by US NIH Grants R01Al050875 and R21Al121700.

Ethics approval and consent to participate

This study was considered exempt by the KAUMS Institutional Review Board.

\section{Consent for publication}

Not applicable.

\section{Competing interests}

$\mathrm{MRH}$ declares the following potential conflicts of interest. Scientific Advisory Boards: Transdermal Cap Inc., Cleveland, OH; BeWell Global Inc., Wan Chai, Hong Kong; Hologenix Inc. Santa Monica, CA;LumiThera Inc., Poulsbo, WA; Vielight, Toronto, Canada; Bright Photomedicine, Sao Paulo, Brazil; Quantum Dynamics LLC, Cambridge, MA; Global Photon Inc., Bee Cave, TX; Medical Coherence, Boston MA; NeuroThera, Newark DE; JOOW Inc., Minneapolis-St. Paul MN; AIRx Medical, Pleasanton CA; FIR Industries, Inc. Ramsey, NJ; UVLRx Therapeutics, Oldsmar, FL; Ultralux UV Inc., Lansing MI; Illumiheal \& Petthera, Shoreline, WA; MB Lasertherapy, Houston, TX; ARRC LED, San Clemente, CA; Varuna Biomedical Corp. Incline Village, NV; Niraxx Light Therapeutics, Inc., Boston, MA. Consulting; Lexington Int, Boca Raton, FL; USHIO Corp, Japan; Merck KGaA, Darmstadt, Germany; Philips Electronics Nederland B.V. Eindhoven, Netherlands; Johnson \& Johnson Inc., Philadelphia, PA; Sanofi-Aventis Deutschland GmbH, Frankfurt am Main, Germany. Stockholdings: Global Photon Inc., Bee Cave, TX; Mitonix, Newark,DE. Other authors declar that there are no conflict of interest.

\section{Author details \\ ${ }^{1}$ Halal Research Center of IRI, FDA, Tehran, Iran. ${ }^{2}$ Student Research Committee, Mashhad University of Medical Sciences, Mashhad, Iran. ${ }^{3}$ Department of Medical Biotechnology, Faculty of Medicine, Mashhad University of Medical Sciences, Mashhad, Iran. ${ }^{4}$ Department of Medical Genetics, School of Medicine, Bam University of Medical Sciences, Bam, Iran. ${ }^{5}$ Department of Medical Immunology, School of Medicine, Tehran University of Medical Sciences, Tehran, Iran. ${ }^{6}$ Student Research Committee, Kashan University of Medical Sciences, Kashan, Iran. ${ }^{7}$ School of Medicine, Kashan University of Medical Sciences, Kashan, Iran. ${ }^{8}$ Neurogenic Inflammation Research Center, Mashhad University of Medical Sciences, Mashhad, Iran. ${ }^{9}$ School of Pharmacy, Mashhad University of Medical Sciences, Mashhad, Iran. ${ }^{10}$ Medical Genetics Research Center, Department of Medical Genetics, Faculty of Medicine, Mashhad University of Medical Sciences, Mashhad, Iran. \\ ${ }^{11}$ Research Center for Biochemistry and Nutrition in Metabolic Diseases, Institute for Basic Sciences, Kashan University of Medical Sciences, Kashan, Iran. ${ }^{12}$ Wellman Center for Photomedicine, Massachusetts General Hospital, Harvard Medical School, 40 Blossom Street, Boston, MA 02114, USA.}

Received: 11 January 2020 Accepted: 27 April 2020

Published online: 09 June 2020

\section{References}

1. Sampetrean O, Saya H. Modeling phenotypes of malignant gliomas. Cancer Sci. 2018;109(1):6-14.

2. Liu KW, Pajtler KW, Worst BC, Pfister SM, Wechsler-Reya RJ. Molecular mechanisms and therapeutic targets in pediatric brain tumors. Sci Signal. 2017;10(470):eaaf7593.

3. McNeill KA. Epidemiology of brain tumors. Neurol Clin. 2016;34(4):981-98.

4. Achey RL, Gittleman H, Schroer J, Khanna V, Kruchko C, Barnholtz-Sloan JS Nonmalignant and malignant meningioma incidence and survival in the 
elderly, 2005-2015, using the central brain tumor registry of the United States. Neuro Oncol. 2019;21(3):380-91.

5. Sung $H$, Siegel RL, Rosenberg PS, Jemal A. Emerging cancer trends among young adults in the USA: analysis of a population-based cancer registry. Lancet Public Health. 2019;4(3):e137-47.

6. del Burgo LS, Hernández RM, Orive G, Pedraz JL. Nanotherapeutic approaches for brain cancer management. Nanomedicine. 2014;10(5):e90519.

7. Petras K, Sejpal S, Sachdev S, Mehta MP. Basic principles of brain tumor radiotherapy. In: Oligodendroglioma. Amsterdam: Elsevier; 2019. p. 245-62.

8. Piccirillo SG, Binda E, Fiocco R, Vescovi AL, Shah K. Brain cancer stem cells. J Mol Med. 2009;87(11):1087.

9. Alexiou GA, Kyritsis AP. Systemic chemotherapy in brain gliomas. In: Epilepsy Surgery and Intrinsic Brain Tumor Surgery. New York: Springer; 2019. p. 261-7.

10. Stewart C, Stewart B, Ware ML. Innovations in metastatic brain tumor treatment. In: Brain and Spinal Tumors-Primary and Secondary. Oxford: IntechOpen; 2019

11. Moeckel S, LaFrance K, Wetsch J, Seliger C, Riemenschneider MJ, Proescholdt M, Hau P, Vollmann-Zwerenz A. ATF4 contributes to autophagy and survival in sunitinib treated brain tumor initiating cells (BTICS). Oncotarget. 2019;10(3):368

12. Zahedi S, Fitzwalter BE, Morin A, Grob S, Desmarais M, Nellan A, Green AL, Vibhakar R, Hankinson TC, Foreman NK. Effect of early-stage autophagy inhibition in BRAF V600E autophagy-dependent brain tumor cells. Cell Death Dis. 2019;10(9):1-15

13. Galluzzi L, Green DR. Autophagy-independent functions of the autophagy machinery. Cell. 2019;177(7):1682-99.

14. Levine B, Kroemer G. Biological functions of autophagy genes: a disease perspective. Cell. 2019;176(1-2):11-42..

15. Morschhauser F, Radford J, Van Hoof A, Botto B, Rohatiner AZ, Salles G, Soubeyran P, Tilly H, Bischof-Delaloye A, van Putten WL. 90Yttriumibritumomab tiuxetan consolidation of first remission in advanced-stage follicular non-Hodgkin lymphoma: updated results after a median follow-up of 7.3 years from the international, randomized, phase III first-line indolent trial. J Clin Oncol. 2013;31(16):1977-83.

16. Denton D, Kumar S. Autophagy-dependent cell death. Cell Death Differ. 2019:26(4):605-16.

17. Mizushima N, Levine B, Cuervo AM, Klionsky DJ. Autophagy fights disease through cellular self-digestion. Nature. 2008;451(7182):1069.

18. Chakradeo S, Sharma K, Alhaddad A, Bakhshwin D, Le N, Harada H, Nakajima W, Yeudall WA, Torti SV, Torti FM. Yet another function of p53-the switch that determines whether radiation-induced autophagy will be cytoprotective or nonprotective: implications for autophagy inhibition as a therapeutic strategy. Mol Pharmacol. 2015;87(5):803-14.

19. Ma X-H, Piao S-F, Dey S, Mcafee Q, Karakousis G, Villanueva J, Hart LS, Levi S, Hu J, Zhang G. Targeting ER stress-induced autophagy overcomes BRAF inhibitor resistance in melanoma. J Clin Invest. 2014; 124(3):1406-17.

20. Li M, Li H, Liu F, Bi R, Tu X, Chen L, Ye S, Cheng X. Characterization of ovarian clear cell carcinoma using target drug-based molecular biomarkers: implications for personalized cancer therapy. J Ovarian Res. 2017;10(1):9.

21. Duffy A, Le J, Sausville E, Emadi A. Autophagy modulation: a target for cancer treatment development. Cancer Chemother Pharmacol. 2015;75(3): 439-47.

22. Eldredge HB, DeNittis A, DuHadaway JB, Chernick M, Metz R, Prendergast GC. Concurrent whole brain radiotherapy and short-course chloroquine in patients with brain metastases: a pilot trial. J Radiat Oncol. 2013;2(3):315-21.

23. Bilger A, Bittner M-I, Grosu A-L, Wiedenmann N, Meyer PT, Firat E, Niedermann G, Weber WA, Milanović D. FET-PET-based reirradiation and chloroquine in patients with recurrent glioblastoma. Strahlenther Onkol. 2014;190(10):957-61.

24. Verbaanderd C, Maes H, Schaaf MB, Sukhatme VP, Pantziarka P, Sukhatme V, Agostinis P, Bouche G. Repurposing Drugs in Oncology (ReDO)—chloroquine and hydroxychloroquine as anti-cancer agents. Ecancermedicalscience. 2017;11:781.

25. Yan Y, Xu Z, Dai S, Qian L, Sun L, Gong Z. Targeting autophagy to sensitive glioma to temozolomide treatment. J Exp Clin Cancer Res. 2016;35(1):23.

26. Levy JMM, Thorburn A. Modulation of pediatric brain tumor autophagy and chemosensitivity. J Neuro-Oncol. 2012:106(2):281-90.
27. Gebert LF, MacRae IJ. Regulation of microRNA function in animals. Nat Rev Mol Cell Biol. 2019;20(1):21-37.

28. Sheu-Gruttadauria J, Pawlica P, Klum SM, Wang S, Yario TA, Oakdale NTS, Steitz JA, MacRae IJ. Structural basis for target-directed microrna degradation. Mol Cell. 2019;75(6):1243-55 e1247.

29. McGeary SE, Lin KS, Shi CY, Pham TM, Bisaria N, Kelley GM, Bartel DP. The biochemical basis of microRNA targeting efficacy. Science. 2019;366(6472): eaav1741.

30. Sana J, Hajduch M, Michalek J, Vyzula R, Slaby O. MicroRNAs and glioblastoma: roles in core signalling pathways and potential clinical implications. J Cell Mol Med. 2011;15(8):1636-44.

31. Kim EH, Jo Y, Sai S, Park M-J, Kim J-Y, Kim JS, Lee Y-J, Cho J-M, Kwak S-Y, Baek J-H. Tumor-treating fields induce autophagy by blocking the Akt2/ miR29b axis in glioblastoma cells. Oncogene. 2019;38(39):6630-46.

32. Jia Y, Lin R, Jin H, Si L, Jian W, Yu Q, Yang S. MicroRNA-34 suppresses proliferation of human ovarian cancer cells by triggering autophagy and apoptosis and inhibits cell invasion by targeting notch 1. Biochimie. 2019; 160:193-9.

33. Wang Z-C, Huang F-Z, Xu H-B, Sun J-C, Wang C-F. MicroRNA-137 inhibits autophagy and chemosensitizes pancreatic cancer cells by targeting ATG5. Int J Biochem Cell Biol. 2019:111:63-71.

34. Wang Y, Zhang S, Dang S, Fang X, Liu M. Overexpression of microRNA-216a inhibits autophagy by targeting regulated MAP $1 S$ in colorectal cancer. Onco Targets Ther. 2019;12:4621.

35. Lin J-F, Chen P-C, Thomas I, Hwang S. Autophagy modulation by dysregulated micrornas in human bladder cancer. Urol Sci. 2019;30(2):46.

36. Frankel LB, Lund AH. MicroRNA regulation of autophagy. Carcinogenesis. 2012;33(11):2018-25

37. Yao D, Jiang Y, Gao S, Shang L, Zhao Y, Huang J, Wang J, Yang S, Chen L. Deconvoluting the complexity of micro RNA $s$ in autophagy to improve potential cancer therapy. Cell Prolif. 2016;49(5):541-53.

38. Eskelinen E-L. Autophagy: supporting cellular and organismal homeostasis by self-eating. Int J Biochem Cell Biol. 2019;111:1-10.

39. Cernigliaro C, D'Anneo A, Carlisi D, Giuliano M, Marino Gammazza A, Barone R, Longhitano L, Cappello F, Emanuele S, Distefano A. Ethanol-mediated stress promotes autophagic survival and aggressiveness of colon cancer cells via activation of nrf2/ho-1 pathway. Cancers. 2019;11(4):505.

40. Wang X, Wu R, Liu Y, Zhao Y, Bi Z, Yao Y, Liu Q, Shi H, Wang F, Wang Y. m6A mRNA methylation controls autophagy and adipogenesis by targeting Atg5 and Atg7. Autophagy. 2019;1-15.

41. Zheng W, Xie W, Yin D, Luo R, Liu M, Guo F. ATG5 and ATG7 induced autophagy interplays with UPR via PERK signaling. Cell Commun Signal. 2019;17(1):42.

42. Wong PM, Puente C, Ganley IG, Jiang X. The ULK1 complex: sensing nutrient signals for autophagy activation. Autophagy. 2013;9(2):124-37.

43. Nishida Y, Arakawa S, Fujitani K, Yamaguchi H, Mizuta T, Kanaseki T, Komatsu M, Otsu K, Tsujimoto Y, Shimizu S. Discovery of Atg5/Atg7-independent alternative macroautophagy. Nature. 2009;461(7264):654-8.

44. Chan EY. mTORC1 phosphorylates the ULK1-mAtg13-FIP200 autophagy regulatory complex. Sci Signal. 2009;2(84):e51.

45. Torii S, Yoshida T, Arakawa S, Honda S, Nakanishi A, Shimizu S. Identification of PPM1D as an essential UIk1 phosphatase for genotoxic stress-induced autophagy. EMBO Rep. 2016;17(11):1552-64.

46. Itakura E, Kishi C, Inoue K, Mizushima N. Beclin 1 forms two distinct phosphatidylinositol 3-kinase complexes with mammalian Atg14 and UVRAG. Mol Biol Cell. 2008;19(12):5360-72.

47. Kabeya Y, Mizushima N, Ueno T, Yamamoto A, Kirisako T, Noda T, Kominami E, Ohsumi Y, Yoshimori T. LC3, a mammalian homologue of yeast Apg8p, is localized in autophagosome membranes after processing. EMBO J. 2000; 19(21):5720-8.

48. Suzuki K, Kubota Y, Sekito T, Ohsumi Y. Hierarchy of Atg proteins in preautophagosomal structure organization. Genes Cells. 2007;12(2):209-18.

49. Geng J, Klionsky DJ. The Atg8 and Atg12 ubiquitin-like conjugation systems in macroautophagy. 'Protein modifications: beyond the usual suspects' review series. EMBO Rep. 2008:9(9):859-64.

50. Ichimura Y, Kirisako T, Takao T, Satomi Y, Shimonishi Y, Ishihara N, Mizushima N, Tanida I, Kominami E, Ohsumi M, et al. A ubiquitin-like system mediates protein lipidation. Nature. 2000:408(6811):488-92.

51. Barth S, Glick D, Macleod KF. Autophagy: assays and artifacts. J Pathol. 2010; 221(2):117-24 
52. Mizushima N, Yoshimori T, Levine B. Methods in mammalian autophagy research. Cell. 2010;140(3):313-26.

53. Klionsky DJ, Abdelmohsen K, Abe A, Abedin MJ, Abeliovich H, Acevedo Arozena A, Adachi H, Adams CM, Adams PD, Adeli K, et al. Guidelines for the use and interpretation of assays for monitoring autophagy (3rd edition). Autophagy. 2016;12(1):1-222.

54. Kabeya Y, Mizushima N, Yamamoto A, Oshitani-Okamoto S, Ohsumi Y, Yoshimori T. LC3, GABARAP and GATE16 localize to autophagosomal membrane depending on form-II formation. J Cell Sci. 2004;117(Pt 13):280512.

55. Li M, Khambu B, Zhang H, Kang J-H, Chen X, Chen D, Vollmer L, Liu P-Q, Vogt $A$, Yin X-M. Suppression of lysosome function induces autophagy via a feedback down-regulation of MTOR complex 1 (MTORC1) activity. J Biol Chem. 2013;288(50):35769-80.

56. Komatsu M, Waguri S, Ueno T, Iwata J, Murata S, Tanida I, Ezaki J, Mizushima $\mathrm{N}$, Ohsumi $\mathrm{Y}$, Uchiyama $\mathrm{Y}$, et al. Impairment of starvation-induced and constitutive autophagy in Atg7-deficient mice. J Cell Biol. 2005;169(3):42534.

57. Kuma A, Hatano M, Matsui M, Yamamoto A, Nakaya H, Yoshimori T, Ohsumi $Y$, Tokuhisa T, Mizushima N. The role of autophagy during the early neonatal starvation period. Nature. 2004:432(7020):1032-6.

58. Jiang P, Nishimura T, Sakamaki Y, Itakura E, Hatta T, Natsume T, Mizushima $\mathrm{N}$. The HOPS complex mediates autophagosome-lysosome fusion through interaction with syntaxin 17. Mol Biol Cell. 2014;25(8):1327-37.

59. Jager S, Bucci C, Tanida I, Ueno T, Kominami E, Saftig P, Eskelinen EL. Role for Rab7 in maturation of late autophagic vacuoles. J Cell Sci. 2004;117(Pt 20):4837-48.

60. Gutierrez MG, Munafo DB, Beron W, Colombo MI. Rab7 is required for the normal progression of the autophagic pathway in mammalian cells. J Cell Sci. 2004;117(Pt 13):2687-97.

61. Diao J, Liu R, Rong Y, Zhao M, Zhang J, Lai Y, Zhou Q, Wilz LM, Li J, Vivona $\mathrm{S}$, et al. ATG14 promotes membrane tethering and fusion of autophagosomes to endolysosomes. Nature. 2015;520(7548):563-6.

62. Itakura E, Kishi-Itakura C, Mizushima N. The hairpin-type tail-anchored SNARE syntaxin 17 targets to autophagosomes for fusion with endosomes/ lysosomes. Cell. 2012;151(6):1256-69.

63. Arakawa S, Honda S, Yamaguchi H, Shimizu S. Molecular mechanisms and physiological roles of Atg5/Atg7-independent alternative autophagy. Proc Jpn Acad Ser B Phys Biol Sci. 2017;93(6):378-85.

64. Riederer MA, Soldati T, Shapiro AD, Lin J, Pfeffer SR. Lysosome biogenesis requires Rab9 function and receptor recycling from endosomes to the trans-Golgi network. J Cell Biol. 1994;125(3):573-82.

65. Lombardi D, Soldati T, Riederer MA, Goda Y, Zerial M, Pfeffer SR. Rab9 functions in transport between late endosomes and the trans Golgi network. EMBO J. 1993;12(2):677-82.

66. Tooze SA, Yoshimori T. The origin of the autophagosomal membrane. Nat Cell Biol. 2010;12(9):831-5.

67. Beau I, Mehrpour M, Codogno P. Autophagosomes and human diseases. Int J Biochem Cell Biol. 2011;43(4):460-4.

68. Klionsky DJ, Cuervo AM, Dunn WA Jr, Levine B, van der Klei I, Seglen PO How shall I eat thee? Autophagy. 2007;3(5):413-6.

69. Orvedahl A, Sumpter R Jr, Xiao G, Ng A, Zou Z, Tang Y, Narimatsu M, Gilpin C, Sun Q, Roth M, et al. Image-based genome-wide siRNA screen identifies selective autophagy factors. Nature. 2011;480(7375):113-7.

70. Noda NN, Kumeta H, Nakatogawa H, Satoo K, Adachi W, Ishii J, Fujioka Y, Ohsumi Y, Inagaki F. Structural basis of target recognition by Atg8/LC3 during selective autophagy. Genes Cells. 2008;13(12):1211-8.

71. Pankiv S, Clausen TH, Lamark T, Brech A, Bruun JA, Outzen H, Øvervatn A, Bjørkøy G, Johansen T. p62/SQSTM1 binds directly to Atg8/LC3 to facilitate degradation of ubiquitinated protein aggregates by autophagy. J Biol Chem. 2007;282(33):24131-45.

72. Ichimura Y, Kumanomidou T, Sou YS, Mizushima T, Ezaki J, Ueno T, Kominami E, Yamane T, Tanaka K, Komatsu M. Structural basis for sorting mechanism of p62 in selective autophagy. J Biol Chem. 2008;283(33):22847-57.

73. Johansen $T$, Lamark T. Selective autophagy mediated by autophagic adapter proteins. Autophagy. 2011;7(3):279-96.

74. Yamaguchi M, Noda NN, Nakatogawa H, Kumeta H, Ohsumi Y, Inagaki F. Autophagy-related protein 8 (Atg8) family interacting motif in Atg3 mediates the Atg3-Atg8 interaction and is crucial for the cytoplasm-tovacuole targeting pathway. J Biol Chem. 2010;285(38):29599-607.
75. Satoo K, Noda NN, Kumeta H, Fujioka Y, Mizushima N, Ohsumi Y, Inagaki F. The structure of Atg4B-LC3 complex reveals the mechanism of LC3 processing and delipidation during autophagy. EMBO J. 2009;28(9):1341-50.

76. Pankiv S, Alemu EA, Brech A, Bruun JA, Lamark T, Overvatn A, Bjørkøy G, Johansen T. FYCO1 is a Rab7 effector that binds to LC3 and PI3P to mediate microtubule plus end-directed vesicle transport. J Cell Biol. 2010;188(2):25369.

77. Gao C, Cao W, Bao L, Zuo W, Xie G, Cai T, Fu W, Zhang J, Wu W, Zhang X, et al. Autophagy negatively regulates Wnt signalling by promoting Dishevelled degradation. Nat Cell Biol. 2010;12(8):781-90.

78. Filimonenko M, Isakson P, Finley KD, Anderson M, Jeong H, Melia TJ, Bartlett $B J$, Myers KM, Birkeland HC, Lamark T, et al. The selective macroautophagic degradation of aggregated proteins requires the PI3P-binding protein Alfy. Mol Cell. 2010;38(2):265-79.

79. Shintani T, Huang WP, Stromhaug PE, Klionsky DJ. Mechanism of cargo selection in the cytoplasm to vacuole targeting pathway. Dev Cell. 2002; 3(6):825-37.

80. Lynch-Day MA, Klionsky DJ. The Cvt pathway as a model for selective autophagy. FEBS Lett. 2010;584(7):1359-66.

81. Suzuki K, Morimoto M, Kondo C, Ohsumi Y. Selective autophagy regulates insertional mutagenesis by the Ty1 retrotransposon in Saccharomyces cerevisiae. Dev Cell. 2011;21 (2):358-65.

82. Monastyrska I, Klionsky DJ. Autophagy in organelle homeostasis: peroxisome turnover. Mol Asp Med. 2006;27(5-6):483-94.

83. He C, Song H, Yorimitsu T, Monastyrska I, Yen WL, Legakis JE, Klionsky DJ. Recruitment of Atg9 to the preautophagosomal structure by Atg11 is essential for selective autophagy in budding yeast. J Cell Biol. 2006;175(6): 925-35.

84. Nice DC, Sato TK, Stromhaug PE, Emr SD, Klionsky DJ. Cooperative binding of the cytoplasm to vacuole targeting pathway proteins, Cvt13 and Cvt20, to phosphatidylinositol 3-phosphate at the pre-autophagosomal structure is required for selective autophagy. J Biol Chem. 2002;277(33):30198-207.

85. Nazarko TY, Farré JC, Subramani S. Peroxisome size provides insights into the function of autophagy-related proteins. Mol Biol Cell. 2009;20(17):382839.

86. Okamoto K, Kondo-Okamoto N, Ohsumi Y. Mitochondria-anchored receptor Atg32 mediates degradation of mitochondria via selective autophagy. Dev Cell. 2009;17(1):87-97.

87. Farré JC, Manjithaya R, Mathewson RD, Subramani S. PpAtg30 tags peroxisomes for turnover by selective autophagy. Dev Cell. 2008;14(3):36576.

88. Morales Quinones M, Winston JT, Stromhaug PE. Propeptide of aminopeptidase 1 protein mediates aggregation and vesicle formation in cytoplasm-to-vacuole targeting pathway. J Biol Chem. 2012;287(13):10121-33.

89. Kirkin V, Lamark T, Sou YS, Bjørkøy G, Nunn JL, Bruun JA, Shvets E, McEwan DG, Clausen TH, Wild P, et al. A role for NBR1 in autophagosomal degradation of ubiquitinated substrates. Mol Cell. 2009;33(4):505-16.

90. Bjørkøy G, Lamark T, Brech A, Outzen H, Perander M, Overvatn A, Stenmark $H$, Johansen T. p62/SQSTM1 forms protein aggregates degraded by autophagy and has a protective effect on huntingtin-induced cell death. J Cell Biol. 2005;171(4):603-14.

91. Reggiori F, Komatsu M, Finley K, Simonsen A. Selective types of autophagy. Int J Cell Biol. 2012:2012:156272.

92. Bartel DP. MicroRNAs: genomics, biogenesis, mechanism, and function. Cell. 2004;116(2):281-97.

93. Mittelbrunn M, Sanchez-Madrid F. Intercellular communication: diverse structures for exchange of genetic information. Nat Rev Mol Cell Biol. 2012; 13(5):328-35.

94. Shalaby T, Grotzer MA. Tumor-associated CSF MicroRNAs for the prediction and evaluation of CNS malignancies. Int J Mol Sci. 2015;16(12):29103-19.

95. Lee Y, Ahn C, Han J, Choi H, Kim J, Yim J, Lee J, Provost P, Radmark O, Kim $\mathrm{S}$, et al. The nuclear RNase III Drosha initiates microRNA processing. Nature. 2003;425(6956):415-9.

96. Doerks T, Copley RR, Schultz J, Ponting CP, Bork P. Systematic identification of novel protein domain families associated with nuclear functions. Genome Res. 2002;12(1):47-56.

97. Macfarlane LA, Murphy PR. MicroRNA: biogenesis, function and role in Cancer. Curr Genomics. 2010;11(7):537-61.

98. Jing Z, Han W, Sui X, Xie J, Pan H. Interaction of autophagy with microRNAs and their potential therapeutic implications in human cancers. Cancer Lett. 2015;356(2):332-8 
99. Ganley IG, Lam DH, Wang J, Ding X, Chen S, Jiang X. ULK1. ATG13. FIP200 complex mediates mTOR signaling and is essential for autophagy. J Biol Chem. 2009;284(18):12297-305.

100. Chen Y, Liersch R, Detmar M. The miR-290-295 cluster suppresses autophagic cell death of melanoma cells. Sci Rep. 2012;2:808.

101. Wu H, Wang F, Hu S, Yin C, Li X, Zhao S, Wang J, Yan X. MiR-20a and miR$106 \mathrm{~b}$ negatively regulate autophagy induced by leucine deprivation via suppression of ULK1 expression in C2C12 myoblasts. Cell Signal. 2012;24(11): 2179-86.

102. Wang Z, Wang N, Liu P, Chen Q, Situ H, Xie T, Zhang J, Peng C, Lin Y, Chen J. MicroRNA-25 regulates chemoresistance-associated autophagy in breast cancer cells, a process modulated by the natural autophagy inducer isoliquiritigenin. Oncotarget. 2014;5(16):7013-26.

103. Tomasetti M, Monaco F, Manzella N, Rohlena J, Rohlenova K, Staffolani S, Gaetani S, Ciarapica V, Amati M, Bracci M, et al. MicroRNA-126 induces autophagy by altering cell metabolism in malignant mesothelioma. Oncotarget. 2016;7(24):36338-52.

104. Huang Y, Chuang AY, Ratovitski EA. Phospho- $\Delta$ Np63a/miR-885-3p axis in tumor cell life and cell death upon cisplatin exposure. Cell Cycle. 2011; 10(22):3938-47.

105. Chatterjee A, Chattopadhyay D, Chakrabarti G. miR-17-5p downregulation contributes to paclitaxel resistance of lung cancer cells through altering beclin1 expression. PLoS One. 2014;9(4):e95716.

106. Menghini R, Casagrande V, Marino A, Marchetti V, Cardellini M, Stoehr R, Rizza S, Martelli E, Greco S, Mauriello A. MiR-216a: a link between endothelial dysfunction and autophagy. Cell Death Dis. 2014;5(1):e1029.

107. Korkmaz G, Le Sage C, Tekirdag KA, Agami R, Gozuacik D. miR-376b controls starvation and mTOR inhibition-related autophagy by targeting ATG4C and BECN1. Autophagy. 2012;8(2):165-76.

108. Tang B, Li N, Gu J, Zhuang Y, Li Q, Wang H-G, Fang Y, Yu B, Zhang J-Y, Xie Q-H. Compromised autophagy by MIR30B benefits the intracellular survival of helicobacter pylori. Autophagy. 2012;8(7):1045-57.

109. Huang Y, Guerrero-Preston R, Ratovitski EA. Phospho- $\Delta$ Np63a-dependent regulation of autophagic signaling through transcription and micro-RNA modulation. Cell Cycle. 2012;11(6):1247-59.

110. Shi G, Shi J, Liu K, Liu N, Wang Y, Fu Z, Ding J, Jia L, Yuan W. Increased miR195 aggravates neuropathic pain by inhibiting autophagy following peripheral nerve injury. Glia. 2013;61(4):504-12.

111. Ravikumar B, Imarisio S, Sarkar S, O'Kane CJ, Rubinsztein DC. Rab5 modulates aggregation and toxicity of mutant huntingtin through macroautophagy in cell and fly models of Huntington disease. J Cell Sci. 2008;121(10):1649-60.

112. Frankel LB, Wen J, Lees $M$, Høyer-Hansen $M$, Farkas T, Krogh $A$, Jäättelä $M$, Lund AH. microRNA-101 is a potent inhibitor of autophagy. EMBO J. 2011; 30(22):4628-41.

113. Korkmaz G, Tekirdag KA, Ozturk DG, Kosar A, Sezerman OU, Gozuacik D. MIR376A is a regulator of starvation-induced autophagy. PLoS One. 2013; 8(12):e82556.

114. Chang Y, Yan W, He X, Zhang L, Li C, Huang H, Nace G, Geller DA, Lin J, Tsung A. miR-375 inhibits autophagy and reduces viability of hepatocellular carcinoma cells under hypoxic conditions. Gastroenterology. 2012;143(1): $177-87$ e 178

115. Comincini S, Allavena G, Palumbo S, Morini M, Durando F, Angeletti F, Pirtoli L. Miracco C. microRNA-17 regulates the expression of ATG7 and modulates the autophagy process, improving the sensitivity to temozolomide and lowdose ionizing radiation treatments in human glioblastoma cells. Cancer Biol Ther. 2013;14(7):574-86.

116. Mikhaylova O, Stratton Y, Hall D, Kellner E, Ehmer B, Drew AF, Gallo CA, Plas DR, Biesiada J, Meller J, et al. VHL-regulated MiR-204 suppresses tumor growth through inhibition of LC3B-mediated autophagy in renal clear cell carcinoma. Cancer Cell. 2012;21(4):532-46.

117. Zhai Z, Wu F, Dong F, Chuang AY, Messer JS, Boone DL, Kwon JH. Human autophagy gene ATG16L1 is post-transcriptionally regulated by MIR142-3p. Autophagy. 2014;10(3):468-79.

118. Lu C, Chen J, Xu HG, Zhou X, He Q, Li YL, Jiang G, Shan Y, Xue B, Zhao RX et al. MIR106B and MIR93 prevent removal of bacteria from epithelial cells by disrupting ATG16L1-mediated autophagy. Gastroenterology. 2014;146(1): 188-99.
119. Tekirdag KA, Korkmaz G, Ozturk DG, Agami R, Gozuacik D. MIR181A regulates starvation- and rapamycin-induced autophagy through targeting of ATG5. Autophagy. 2013;9(3):374-85.

120. Nguyen HT, Dalmasso G, Müller S, Carrière J, Seibold F, Darfeuille-Michaud A. Crohn's disease-associated adherent invasive Escherichia coli modulate levels of microRNAs in intestinal epithelial cells to reduce autophagy. Gastroenterology. 2014;146(2):508-19.

121. Kovaleva V, Mora R, Park YJ, Plass C, Chiramel Al, Bartenschlager R, Döhner H, Stilgenbauer S, Pscherer A, Lichter P, et al. miRNA-130a targets ATG2B and DICER1 to inhibit autophagy and trigger killing of chronic lymphocytic leukemia cells. Cancer Res. 2012;72(7):1763-72.

122. Yang J, Chen D, He Y, Meléndez A, Feng Z, Hong Q, Bai X, Li Q, Cai G, Wang $J$, et al. MiR-34 modulates Caenorhabditis elegans lifespan via repressing the autophagy gene atg9. Age (Dordrecht, Netherlands). 2013;35(1):11-22.

123. Wu Z, Lu H, Sheng J, Li L. Inductive microRNA-21 impairs anti-mycobacterial responses by targeting IL-12 and BCl-2. FEBS Lett. 2012;586(16):2459-67.

124. Tian L, Zhang J, Ge J, Xiao H, Lu J, Fu S, Liu M, Sun Y. MicroRNA-205 suppresses proliferation and promotes apoptosis in laryngeal squamous cell carcinoma. Med Oncol (Northwood, London, England). 2014;31(1):785.

125. Li L, Yuan L, Luo J, Gao J, Guo J, Xie X. MiR-34a inhibits proliferation and migration of breast cancer through down-regulation of BCl-2 and SIRT1. Clin Exp Med. 2013;13(2):109-17.

126. Yan D, Dong XD, Chen X, Yao S, Wang L, Wang J, Wang C, Hu DN, Qu J, Tu L. Role of microRNA-182 in posterior uveal melanoma: regulation of tumor development through MITF, BCL2 and cyclin D2. PLoS One. 2012;7(7): e40967.

127. Wan G, Xie W, Liu Z, Xu W, Lao Y, Huang N, Cui K, Liao M, He J, Jiang Y, et al. Hypoxia-induced MIR155 is a potent autophagy inducer by targeting multiple players in the MTOR pathway. Autophagy. 2014;10(1):70-9.

128. Ge YY, Shi Q, Zheng ZY, Gong J, Zeng C, Yang J, Zhuang SM. MicroRNA-100 promotes the autophagy of hepatocellular carcinoma cells by inhibiting the expression of mTOR and IGF-1R. Oncotarget. 2014;5(15):6218-28.

129. Roccaro AM, Sacco A, Jia X, Azab AK, Maiso P, Ngo HT, Azab F, Runnels J, Quang P, Ghobrial IM. microRNA-dependent modulation of histone acetylation in Waldenstrom macroglobulinemia. Blood. 2010;116(9):1506-14.

130. Chio CC, Lin JW, Cheng HA, Chiu WT, Wang YH, Wang JJ, Hsing CH, Chen RM. MicroRNA-210 targets antiapoptotic BCl-2 expression and mediates hypoxia-induced apoptosis of neuroblastoma cells. Arch Toxicol. 2013;87(3): $459-68$.

131. Shan B, Yao TP, Nguyen HT, Zhuo Y, Levy DR, Klingsberg RC, Tao H, Palmer ML, Holder KN, Lasky JA. Requirement of HDAC6 for transforming growth factor-beta1-induced epithelial-mesenchymal transition. J Biol Chem. 2008; 283(30):21065-73.

132. Lee Y-S, Lim K-H, Guo X, Kawaguchi Y, Gao Y, Barrientos T, Ordentlich P, Wang X-F, Counter CM, Yao T-P. The cytoplasmic deacetylase HDAC6 is required for efficient oncogenic tumorigenesis. Cancer Res. 2008;68(18): 7561-9.

133. Yang Y, Sun Y, Wang H, Li H, Zhang M, Zhou L, Meng X, Wu Y, Liu P, Liu X, et al. MicroRNA-221 induces autophagy through suppressing HDAC6 expression and promoting apoptosis in pancreatic cancer. Oncol Lett. 2018; 16(6):7295-301.

134. Islam Khan MZ, Tam SY, Law HKW. Autophagy-modulating long non-coding RNAs (LncRNAs) and their molecular events in cancer. Front Genet. 2019;9: 750.

135. YiRen $H$, YingCong $Y$, Sunwu $Y$, Keqin $L$, Xiaochun $T$, Senrui $C$, Ende $C$, XiZhou L, Yanfan C. Long noncoding RNA MALAT1 regulates autophagy associated chemoresistance via miR-23b-3p sequestration in gastric cancer. Mol Cancer. 2017;16(1):174.

136. Huang X, Xiao R, Pan S, Yang X, Yuan W, Tu Z, Xu M, Zhu Y, Yin Q, Wu Y. Uncovering the roles of long non-coding RNAs in cancer stem cells. J Hematol Oncol. 2017;10(1):62.

137. Fu Z, Luo W, Wang J, Peng T, Sun G, Shi J, Li Z, Zhang B. Malat1 activates autophagy and promotes cell proliferation by sponging miR-101 and upregulating STMN1, RAB5A and ATG4D expression in glioma. Biochem Biophys Res Commun. 2017:492(3):480-6.

138. Yuan P, Cao W, Zang Q, Li G, Guo X, Fan J. The HIF-2a-MALAT1-miR-216b axis regulates multi-drug resistance of hepatocellular carcinoma cells via modulating autophagy. Biochem Biophys Res Commun. 2016;478(3):1067-73.

139. Gu J, Wang Y, Wang X, Zhou D, Wang X, Zhou M, He Z. Effect of the LncRNA GAS5-MiR-23a-ATG3 axis in regulating autophagy in patients with breast cancer. Cell Physiol Biochem. 2018;48(1):194-207. 
140. Tassinari V, Cesarini V, Silvestris DA, Gallo A. The adaptive potential of RNA editing-mediated miRNA-retargeting in cancer. Biochim Biophys Acta Gene Regul Mech. 2019;1862(3):291-300.

141. Liang $H$. The role of A-to-I RNA editing in diversifying the microRNA functions in cancer. In: AACR; 2019.

142. Xu X, Wang Y, Mojumdar K, Zhou Z, Jeong KJ, Mangala LS, Yu S, Tsang YH, Rodriguez-Aguayo C, Lu Y. A-to-I-edited miRNA-379-5p inhibits cancer cell proliferation through CD97-induced apoptosis. J Clin Investig. 2019;129(12): 5343-56.

143. Bhattacharya A, Schmitz U, Raatz Y, Schonherr M, Kottek T, Schauer M, Franz S, Saalbach A, Anderegg U, Wolkenhauer O, et al. miR-638 promotes melanoma metastasis and protects melanoma cells from apoptosis and autophagy. Oncotarget. 2015;6(5):2966-80.

144. Nyhan MJ, O'Donovan TR, Boersma AW, Wiemer EA, McKenna SL. MiR-193b promotes autophagy and non-apoptotic cell death in oesophageal cancer cells. BMC Cancer. 2016;16:101.

145. Fujiwara N, Inoue J, Kawano T, Tanimoto K, Kozaki K, Inazawa J. miR-634 activates the mitochondrial apoptosis pathway and enhances chemotherapy-induced cytotoxicity. Cancer Res. 2015;75(18):3890-901.

146. Huang Y, Guerrero-Preston R, Ratovitski EA. Phospho-DeltaNp63alphadependent regulation of autophagic signaling through transcription and micro-RNA modulation. Cell cycle (Georgetown, Tex). 2012;11(6):1247-59.

147. Huang Y, Chuang AY, Ratovitski EA. Phospho-DeltaNp63alpha/miR-885-3p axis in tumor cell life and cell death upon cisplatin exposure. Cell Cycle (Georgetown, Tex). 2011;10(22):3938-47.

148. Fujiya M, Konishi H, Mohamed Kamel MK, Ueno N, Inaba Y, Moriichi K, Tanabe H, Ikuta K, Ohtake T, Kohgo Y. microRNA-18a induces apoptosis in colon cancer cells via the autophagolysosomal degradation of oncogenic heterogeneous nuclear ribonucleoprotein A1. Oncogene. 2014;33(40):484756.

149. Zhang H, Tang J, Li C, Kong J, Wang J, Wu Y, Xu E, Lai M. MiR-22 regulates 5-FU sensitivity by inhibiting autophagy and promoting apoptosis in colorectal cancer cells. Cancer Lett. 2015;356(2 Pt B):781-90.

150. Zhai Z, Wu F, Chuang AY, Kwon JH. miR-106b fine tunes ATG16L1 expression and autophagic activity in intestinal epithelial HCT116 cells. Inflamm Bowel Dis. 2013;19(11):2295-301.

151. Huangfu L, Liang H, Wang G, Su X, Li L, Du Z, Hu M, Dong Y, Bai X, Liu T, et al. miR-183 regulates autophagy and apoptosis in colorectal cancer through targeting of UVRAG. Oncotarget. 2016;7(4):4735-45.

152. Tan S, Shi H, Ba M, Lin S, Tang H, Zeng X, Zhang X. miR-409-3p sensitizes colon cancer cells to oxaliplatin by inhibiting Beclin-1-mediated autophagy. Int J Mol Med. 2016;37(4):1030-8.

153. Zhai $H$, Song B, Xu X, Zhu W, Ju J. Inhibition of autophagy and tumor growth in colon cancer by miR-502. Oncogene. 2013;32(12):1570-9.

154. Du F, Feng Y, Fang J, Yang M. MicroRNA-143 enhances chemosensitivity of Quercetin through autophagy inhibition via target GABARAPL1 in gastric cancer cells. Biomed Pharmacother. 2015;74:169-77.

155. Zhao J, Nie Y, Wang H, Lin Y. MiR-181a suppresses autophagy and sensitizes gastric cancer cells to cisplatin. Gene. 2016;576(2 Pt 2):828-33.

156. Tazawa H, Yano S, Yoshida R, Yamasaki Y, Sasaki T, Hashimoto Y, Kuroda S, Ouchi M, Onishi T, Uno F, et al. Genetically engineered oncolytic adenovirus induces autophagic cell death through an E2F1-microRNA-7-epidermal growth factor receptor axis. Int J Cancer. 2012;131(12):2939-50.

157. Chatterjee A, Chattopadhyay D, Chakrabarti G. MiR-16 targets BCl-2 in paclitaxel-resistant lung cancer cells and overexpression of miR-16 along with miR-17 causes unprecedented sensitivity by simultaneously modulating autophagy and apoptosis. Cell Signal. 2015;27(2):189-203.

158. Wei J, Ma Z, Li Y, Zhao B, Wang D, Jin Y, Jin Y. miR-143 inhibits cell proliferation by targeting autophagy-related $2 B$ in non-small cell lung cancer H1299 cells. Mol Med Rep. 2015;11(1):571-6.

159. Chen S, Li P, Li J, Wang Y, Du Y, Chen X, Zang W, Wang H, Chu H, Zhao G, et al. MiR-144 inhibits proliferation and induces apoptosis and autophagy in lung cancer cells by targeting TIGAR. Cell Physiol Biochem. 2015;35(3):9971007.

160. Pan B, Feng B, Chen Y, Huang G, Wang R, Chen L, Song H. MiR-200b regulates autophagy associated with chemoresistance in human lung adenocarcinoma. Oncotarget. 2015;6(32):32805-20.

161. Chen K, Shi W. Autophagy regulates resistance of non-small cell lung cancer cells to paclitaxel. Tumour Biol. 2016;37(8):10539-44.
162. Wang R, Wang ZX, Yang JS, Pan X, De W, Chen LB. MicroRNA-451 functions as a tumor suppressor in human non-small cell lung cancer by targeting ras-related protein 14 (RAB14). Oncogene. 2011;30(23):2644-58.

163. Bao L, Lv L, Feng J, Chen Y, Wang $X$, Han S, Zhao H. miR-487b-5p regulates Temozolomide resistance of lung Cancer cells through LAMP2-medicated autophagy. DNA Cell Biol. 2016;35(8):385-92.

164. Yi H, Liang B, Jia J, Liang N, Xu H, Ju G, Ma S, Liu X. Differential roles of miR$199 a-5 p$ in radiation-induced autophagy in breast cancer cells. FEBS Lett. 2013;587(5):436-43.

165. Sun Q, Liu T, Yuan Y, Guo Z, Xie G, Du S, Lin X, Xu Z, Liu M, Wang W, et al. MiR-200c inhibits autophagy and enhances radiosensitivity in breast cancer cells by targeting UBQLN1. Int J Cancer. 2015;136(5):1003-12.

166. Feng L, Ma Y, Sun J, Shen Q, Liu L, Lu H, Wang F, Yue Y, Li J, Zhang S, et al. YY1-MIR372-SQSTM1 regulatory axis in autophagy. Autophagy. 2014;10(8): $1442-53$.

167. Liu ZR, Song Y, Wan LH, Zhang YY, Zhou LM. Over-expression of miR-451a can enhance the sensitivity of breast cancer cells to tamoxifen by regulating 14-3-3zeta, estrogen receptor alpha, and autophagy. Life Sci. 2016;149:104-13.

168. He J, Yu JJ, Xu Q, Wang L, Zheng JZ, Liu LZ, Jiang BH. Downregulation of ATG14 by EGR1-MIR152 sensitizes ovarian cancer cells to cisplatin-induced apoptosis by inhibiting cyto-protective autophagy. Autophagy. 2015;11(2): 373-84.

169. Zhang Y, Zhao FJ, Chen LL, Wang LQ, Nephew KP, Wu YL, Zhang S. MiR-373 targeting of the Rab22a oncogene suppresses tumor invasion and metastasis in ovarian cancer. Oncotarget. 2014;5(23):12291-303.

170. Huang N, Wu J, Qiu W, Lyu Q, He J, Xie W, Xu N, Zhang Y. MiR-15a and miR-16 induce autophagy and enhance chemosensitivity of Camptothecin. Cancer Biol Ther. 2015;16(6):941-8.

171. Zhao S, Yao D, Chen J, Ding N, Ren F. MiR-20a promotes cervical cancer proliferation and metastasis in vitro and in vivo. PLoS One. 2015;10(3): e0120905.

172. Fang W, Shu S, Yongmei L, Endong Z, Lirong Y, Bei S. miR-224-3p inhibits autophagy in cervical cancer cells by targeting FIP200. Sci Rep. 2016;6: 33229.

173. Ran X, Yang J, Liu C, Zhou P, Xiao L, Zhang K. MiR-218 inhibits HMGB1mediated autophagy in endometrial carcinoma cells during chemotherapy. Int J Clin Exp Pathol. 2015;8(6):6617-26.

174. Ma Y, Yang HZ, Dong BJ, Zou HB, Zhou Y, Kong XM, Huang YR. Biphasic regulation of autophagy by miR-96 in prostate cancer cells under hypoxia. Oncotarget. 2014;5(19):9169-82.

175. Gu H, Liu M, Ding C, Wang X, Wang R, Wu X, Fan R. Hypoxia-responsive miR-124 and miR-144 reduce hypoxia-induced autophagy and enhance radiosensitivity of prostate cancer cells via suppressing PIM1. Cancer Med. 2016;5(6):1174-82.

176. He C, Dong X, Zhai B, Jiang X, Dong D, Li B, Jiang H, Xu S, Sun X. MiR-21 mediates sorafenib resistance of hepatocellular carcinoma cells by inhibiting autophagy via the PTEN/Akt pathway. Oncotarget. 2015;6(30):28867-81.

177. Xu L, Beckebaum S, lacob S, Wu G, Kaiser GM, Radtke A, Liu C, Kabar I, Schmidt HH, Zhang X, et al. MicroRNA-101 inhibits human hepatocellular carcinoma progression through $\mathrm{EZH} 2$ downregulation and increased cytostatic drug sensitivity. J Hepatol. 2014;60(3):590-8.

178. Xu N, Zhang J, Shen C, Luo Y, Xia L, Xue F, Xia Q. Cisplatin-induced downregulation of miR-199a-5p increases drug resistance by activating autophagy in HCC cell. Biochem Biophys Res Commun. 2012;423(4):826-31.

179. Lan SH, Wu SY, Zuchini R, Lin XZ, Su IJ, Tsai TF, Lin YJ, Wu CT, Liu HS. Autophagy suppresses tumorigenesis of hepatitis B virus-associated hepatocellular carcinoma through degradation of microRNA-224. Hepatology (Baltimore, Md). 2014;59(2):505-17.

180. Wang P, Zhang J, Zhang L, Zhu Z, Fan J, Chen L, Zhuang L, Luo J, Chen H, Liu $L$, et al. MicroRNA 23b regulates autophagy associated with radioresistance of pancreatic cancer cells. Gastroenterology. 2013;145(5): $1133-43$ e 1112.

181. Zhang X, Shi H, Lin S, Ba M, Cui S. MicroRNA-216a enhances the radiosensitivity of pancreatic cancer cells by inhibiting beclin-1-mediated autophagy. Oncol Rep. 2015;34(3):1557-64.

182. Hall DP, Cost NG, Hegde S, Kellner E, Mikhaylova O, Stratton Y, Ehmer B, Abplanalp WA, Pandey R, Biesiada J, et al. TRPM3 and miR-204 establish a regulatory circuit that controls oncogenic autophagy in clear cell renal cell carcinoma. Cancer Cell. 2014:26(5):738-53. 
183. Gundara JS, Zhao J, Gill AJ, Lee JC, Delbridge L, Robinson BG, McLean C, Serpell J, Sidhu SB. Noncoding RNA blockade of autophagy is therapeutic in medullary thyroid cancer. Cancer Med. 2015;4(2):174-82.

184. Chen CL, Tseng YW, Wu JC, Chen GY, Lin KC, Hwang SM, Hu YC. Suppression of hepatocellular carcinoma by baculovirus-mediated expression of long non-coding RNA PTENP1 and MicroRNA regulation. Biomaterials. 2015;44:71-81.

185. Kaza N, Kohli L, Roth KA. Autophagy in brain tumors: a new target for therapeutic intervention. Brain Pathol (Zurich, Switzerland). 2012;22(1):89-98.

186. Servante J, Estranero J, Meijer L, Layfield R, Grundy R. Chemical modulation of autophagy as an adjunct to chemotherapy in childhood and adolescent brain tumors. Oncotarget. 2018;9(81):35266-77.

187. Verhaak RG, Hoadley KA, Purdom E, Wang V, Qi Y, Wilkerson MD, Miller CR, Ding L, Golub T, Mesirov JP, et al. Integrated genomic analysis identifies clinically relevant subtypes of glioblastoma characterized by abnormalities in PDGFRA, IDH1, EGFR, and NF1. Cancer Cell. 2010;17(1):98-110.

188. Cheng CK, Fan QW, Weiss WA. PI3K signaling in glioma--animal models and therapeutic challenges. Brain Pathol (Zurich, Switzerland). 2009;19(1):112-20.

189. Franceschi E, Cavallo G, Lonardi S, Magrini E, Tosoni A, Grosso D, Scopece L, Blatt $\mathrm{V}$, Urbini B, Pession A, et al. Gefitinib in patients with progressive highgrade gliomas: a multicentre phase II study by Gruppo Italiano Cooperativo di neuro-Oncologia (GICNO). Br J Cancer. 2007;96(7):1047-51.

190. Prados MD, Lamborn KR, Chang S, Burton E, Butowski N, Malec M, Kapadia A, Rabbitt J, Page MS, Fedoroff A, et al. Phase 1 study of erlotinib $\mathrm{HCl}$ alone and combined with temozolomide in patients with stable or recurrent malignant glioma. Neuro Oncol. 2006;8(1):67-78.

191. Rich JN, Reardon DA, Peery T, Dowell JM, Quinn JA, Penne KL, Wikstrand CJ, Van Duyn LB, Dancey JE, McLendon RE, et al. Phase II trial of gefitinib in recurrent glioblastoma. J Clin Oncol. 2004;22(1):133-42.

192. Pillay V, Allaf L, Wilding AL, Donoghue JF, Court NW, Greenall SA, Scott AM, Johns TG. The plasticity of oncogene addiction: implications for targeted therapies directed to receptor tyrosine kinases. Neoplasia (New York, NY). 2009;11(5):448-58 442 p following 458.

193. Carrasco-Garcia E, Saceda M, Grasso S, Rocamora-Reverte L, Conde M, Gomez-Martinez A, Garcia-Morales P, Ferragut JA, Martinez-Lacaci I. Small tyrosine kinase inhibitors interrupt EGFR signaling by interacting with erbB3 and erbB4 in glioblastoma cell lines. Exp Cell Res. 2011;317(10):1476-89.

194. Fan QW, Cheng CK, Nicolaides TP, Hackett CS, Knight ZA, Shokat KM, Weiss WA. A dual phosphoinositide-3-kinase alpha/mTOR inhibitor cooperates with blockade of epidermal growth factor receptor in PTEN-mutant glioma. Cancer Res. 2007:67(17):7960-5.

195. Mellinghoff IK, Cloughesy TF, Mischel PS. PTEN-mediated resistance to epidermal growth factor receptor kinase inhibitors. Clin Cancer Res. 2007; 13(2 Pt 1):378-81.

196. Wang MY, Lu KV, Zhu S, Dia EQ, Vivanco I, Shackleford GM, Cavenee WK, Mellinghoff IK, Cloughesy TF, Sawyers CL, et al. Mammalian target of rapamycin inhibition promotes response to epidermal growth factor receptor kinase inhibitors in PTEN-deficient and PTEN-intact glioblastoma cells. Cancer Res. 2006;66(16):7864-9.

197. Chang SM, Wen P, Cloughesy T, Greenberg H, Schiff D, Conrad C, Fink K, Robins HI, De Angelis L, Raizer J, et al. Phase II study of CCl-779 in patients with recurrent glioblastoma multiforme. Investig New Drugs. 2005;23(4): 357-61

198. Fan QW, Knight ZA, Goldenberg DD, Yu W, Mostov KE, Stokoe D, Shokat KM, Weiss WA. A dual PI3 kinase/mTOR inhibitor reveals emergent efficacy in glioma. Cancer Cell. 2006;9(5):341-9.

199. Degtyarev M, De Maziere A, Orr C, Lin J, Lee BB, Tien JY, Prior WW, van Dijk S, Wu H, Gray DC, et al. Akt inhibition promotes autophagy and sensitizes PTEN-null tumors to lysosomotropic agents. J Cell Biol. 2008;183(1):101-16.

200. Fan QW, Cheng C, Hackett C, Feldman M, Houseman BT, Nicolaides T, HaasKogan D, James CD, Oakes SA, Debnath J, et al. Akt and autophagy cooperate to promote survival of drug-resistant glioma. Sci Signal. 2010; 3(147):ra81.

201. Eimer S, Belaud-Rotureau MA, Airiau K, Jeanneteau M, Laharanne E, Veron N, Vital A, Loiseau H, Merlio JP, Belloc F. Autophagy inhibition cooperates with erlotinib to induce glioblastoma cell death. Cancer Biol Ther. 2011;11(12): 1017-27.

202. Shingu T, Fujiwara K, Bogler O, Akiyama Y, Moritake K, Shinojima N, Tamada Y, Yokoyama T, Kondo S. Inhibition of autophagy at a late stage enhances imatinib-induced cytotoxicity in human malignant glioma cells. Int J Cancer. 2009;124(5):1060-71.

203. Kanzawa T, Zhang L, Xiao L, Germano IM, Kondo Y, Kondo S. Arsenic trioxide induces autophagic cell death in malignant glioma cells by upregulation of mitochondrial cell death protein BNIP3. Oncogene. 2005; 24(6):980-91.

204. Daido S, Kanzawa T, Yamamoto A, Takeuchi H, Kondo Y, Kondo S. Pivotal role of the cell death factor BNIP3 in ceramide-induced autophagic cell death in malignant glioma cells. Cancer Res. 2004;64(12):4286-93.

205. Kim EH, Sohn S, Kwon HJ, Kim SU, Kim MJ, Lee SJ, Choi KS. Sodium selenite induces superoxide-mediated mitochondrial damage and subsequent autophagic cell death in malignant glioma cells. Cancer Res. 2007;67(13): 6314-24.

206. Salazar M, Carracedo A, Salanueva IJ, Hernandez-Tiedra S, Lorente M, Egia A, Vazquez P, Blazquez C, Torres S, Garcia S, et al. Cannabinoid action induces autophagy-mediated cell death through stimulation of ER stress in human glioma cells. J Clin Invest. 2009;119(5):1359-72.

207. Hetschko H, Voss V, Senft C, Seifert V, Prehn JH, Kogel D. BH3 mimetics reactivate autophagic cell death in anoxia-resistant malignant glioma cells. Neoplasia (New York, NY). 2008;10(8):873-85.

208. Voss V, Senft C, Lang V, Ronellenfitsch MW, Steinbach JP, Seifert V, Kogel D. The pan-Bcl-2 inhibitor (-)-gossypol triggers autophagic cell death in malignant glioma. Mol Cancer Res. 2010;8(7):1002-16.

209. Szybka M, Zawlik I, Kulczycka D, Golanska E, Jesien E, Kupnicka D, Stawski R, Piaskowski S, Bieniek E, Zakrzewska M, et al. Elimination of wild-type P53 mRNA in glioblastomas showing heterozygous mutations of $\mathrm{P} 53 . \mathrm{Br} J$ Cancer. 2008;98(8):1431-3.

210. Geng Y, Kohli L, Klocke BJ, Roth KA. Chloroquine-induced autophagic vacuole accumulation and cell death in glioma cells is p53 independent. Neuro Oncol. 2010;12(5):473-81.

211. Kang KB, Zhu C, Yong SK, Gao Q, Wong MC. Enhanced sensitivity of celecoxib in human glioblastoma cells: induction of DNA damage leading to p53dependent G1 cell cycle arrest and autophagy. Mol Cancer. 2009;8:66.

212. Saadatpour L, Fadaee E, Fadaei S, Nassiri Mansour R, Mohammadi M, Mousavi SM, Goodarzi M, Verdi J, Mirzaei H. Glioblastoma: exosome and microRNA as novel diagnosis biomarkers. Cancer Gene Ther. 2016;23(12): 415-8.

213. Masoudi MS, Mehrabian E, Mirzaei H. MiR-21: A key player in glioblastoma pathogenesis. J Cell Biochem. 2018;119(2):1285-90.

214. Lathia JD, Mack SC, Mulkearns-Hubert EE, Valentim CL, Rich JN. Cancer stem cells in glioblastoma. Genes Dev. 2015;29(12):1203-17.

215. Wang Q, Hu B, Hu X, Kim H, Squatrito M, Scarpace L, deCarvalho AC, Lyu S, Li P, Li Y, et al. Tumor Evolution of Glioma-Intrinsic Gene Expression Subtypes Associates with Immunological Changes in the Microenvironment. Cancer Cell. 2017;32(1):42-56 e46.

216. Laks DR, Crisman TJ, Shih MY, Mottahedeh J, Gao F, Sperry J, Garrett MC, Yong WH, Cloughesy TF, Liau LM, et al. Large-scale assessment of the gliomasphere model system. Neuro Oncol. 2016;18(10):1367-78.

217. Mao P, Joshi K, Li J, Kim SH, Li P, Santana-Santos L, Luthra S, Chandran UR, Benos PV, Smith L, et al. Mesenchymal glioma stem cells are maintained by activated glycolytic metabolism involving aldehyde dehydrogenase $1 \mathrm{~A} 3$. Proc Natl Acad Sci U S A. 2013;110(21):8644-9.

218. Huang T, Kim CK, Alvarez AA, Pangeni RP, Wan X, Song X, Shi T, Yang $Y$, Sastry N, Horbinski CM, et al. MST4 Phosphorylation of ATG4B Regulates Autophagic Activity, Tumorigenicity, and Radioresistance in Glioblastoma. Cancer Cell. 2017;32(6):840-55 e848.

219. Jiang L, Wang C, Lei F, Zhang L, Zhang X, Liu A, Wu G, Zhu J, Song L. miR93 promotes cell proliferation in gliomas through activation of PI3K/Akt signaling pathway. Oncotarget. 2015;6(10):8286-99.

220. Fang L, Deng Z, Shatseva T, Yang J, Peng C, Du WW, Yee AJ, Ang LC, He C, Shan SW, et al. MicroRNA miR-93 promotes tumor growth and angiogenesis by targeting integrin-beta8. Oncogene. 2011;30(7):806-21.

221. Yu XF, Zou J, Bao ZJ, Dong J. miR-93 suppresses proliferation and colony formation of human colon cancer stem cells. World J Gastroenterol. 2011 ; 17(42):4711-7.

222. Liu S, Patel SH, Ginestier C, Ibarra I, Martin-Trevino R, Bai S, McDermott SP, Shang L, Ke J, Ou SJ, et al. MicroRNA93 regulates proliferation and differentiation of normal and malignant breast stem cells. PLoS Genet. 2012;8(6):e1002751. 
223. Huang $T$, Wan $X$, Alvarez AA, James CD, Song X, Yang Y, Sastry N. MIR93 (microRNA -93) regulates tumorigenicity and therapy response of glioblastoma by targeting autophagy. PLoS Genet. 2012;8(6):e1002751 .

224. Zhu H, Wu H, Liu X, Li B, Chen Y, Ren X, Liu CG, Yang JM. Regulation of autophagy by a beclin 1-targeted microRNA, miR-30a, in cancer cells. Autophagy. 2009;5(6):816-23.

225. Xu J, Huang H, Peng R, Ding X, Jiang B, Yuan X, Xi J. MicroRNA-30a increases the chemosensitivity of U251 glioblastoma cells to temozolomide by directly targeting beclin 1 and inhibiting autophagy. Exp Ther Med. 2018:15(6):4798-804.

226. Ravishankar D, Rajora AK, Greco F, Osborn HM. Flavonoids as prospective compounds for anti-cancer therapy. Int J Biochem Cell Biol. 2013;45(12): 2821-31.

227. Lin Y, Shi R, Wang X, Shen HM. Luteolin, a flavonoid with potential for cancer prevention and therapy. Curr Cancer Drug Targets. 2008;8(7):634-46.

228. Shimoi K, Okada H, Furugori M, Goda T, Takase S, Suzuki M, Hara Y, Yamamoto H, Kinae N. Intestinal absorption of luteolin and luteolin 7-Obeta-glucoside in rats and humans. FEBS Lett. 1998;438(3):220-4.

229. Wruck CJ, Claussen M, Fuhrmann G, Romer L, Schulz A, Pufe T, Waetzig V, Peipp M, Herdegen T, Gotz ME. Luteolin protects rat PC12 and C6 cells against MPP+ induced toxicity via an ERK dependent Keap1-Nrf2-ARE pathway. J Neural Transm Suppl. 2007;72:57-67.

230. Chakrabarti M, Ray SK. Anti-tumor activities of luteolin and silibinin in glioblastoma cells: overexpression of miR-7-1-3p augmented luteolin and silibinin to inhibit autophagy and induce apoptosis in glioblastoma in vivo. Apoptosis. 2016;21(3):312-28.

231. Nallamshetty S, Chan SY, Loscalzo J. Hypoxia: a master regulator of microRNA biogenesis and activity. Free Radic Biol Med. 2013;64:20-30.

232. Guo X, Xue H, Guo X, Gao X, Xu S, Yan S, Han X, Li T, Shen J, Li G. MiR224$3 p$ inhibits hypoxia-induced autophagy by targeting autophagy-related genes in human glioblastoma cells. Oncotarget. 2015;6(39):41620-37.

233. Fong B, Barkhoudarian G, Pezeshkian P, Parsa AT, Gopen Q, Yang I. The molecular biology and novel treatments of vestibular schwannomas. J Neurosurg. 2011;115(5):906-14.

234. Yang $P$, Sun D, Jiang F. Ailanthone promotes human vestibular schwannoma cell apoptosis and autophagy by downregulation of miR-21. Oncol Res. 2018;26(6):941-8.

235. Cavalli FMG, Remke M, Rampasek L, Peacock J, Shih DJH, Luu B, Garzia L, Torchia J, Nor C, Morrissy AS, et al. Intertumoral Heterogeneity within Medulloblastoma Subgroups. Cancer Cell. 2017:31(6):737-54 e736.

236. Singh SV, Dakhole AN, Deogharkar A, Kazi S, Kshirsagar R, Goel A, Moiyadi A, Jalali R, Sridhar E, Gupta T, et al. Restoration of miR-30a expression inhibits growth, tumorigenicity of medulloblastoma cells accompanied by autophagy inhibition. Biochem Biophys Res Commun. 2017;491(4):946-52.

237. Huang T, Wan X, Alvarez AA, James CD, Song X, Yang Y, Sastry N, Nakano I, Sulman EP, Hu B. MIR93 (microRNA-93) Regulates Tumorigenicity and Therapy Response of Glioblastoma by Targeting Autophagy. Autophagy. 2019;15(6):1100-11.

238. Huang S, Qi P, Zhang T, Li F, He X. The HIF-1a/miR-224-3p/ATG5 axis affects cell mobility and chemosensitivity by regulating hypoxia-induced protective autophagy in glioblastoma and astrocytoma. Oncol Rep. 2019;41(3):1759-68.

239. Huang D, Qiu S, Ge R, He L, Li M, Li Y, Peng Y. miR-340 suppresses glioblastoma multiforme. Oncotarget. 2015;6(11):9257.

240. Lu Y, Xiao L, Liu Y, Wang H, Li H, Zhou Q, Pan J, Lei B, Huang A, Qi S. MIR517C inhibits autophagy and the epithelial-to-mesenchymal (-like) transition phenotype in human glioblastoma through KPNA2-dependent disruption of TP53 nuclear translocation. Autophagy. 2015;11(12):2213-32.

241. Stojcheva N, Schechtmann G, Sass S, Roth P, Florea A-M, Stefanski A, Stühler K, Wolter M, Müller NS, Theis FJ. MicroRNA-138 promotes acquired alkylator resistance in glioblastoma by targeting the $\mathrm{Bcl}-2$-interacting mediator BIM. Oncotarget. 2016;7(11):12937.

242. Xue H, Yuan G, Guo X, Liu Q, Zhang J, Gao X, Guo X, Xu S, Li T, Shao Q. A novel tumor-promoting mechanism of IL6 and the therapeutic efficacy of tocilizumab: hypoxia-induced IL6 is a potent autophagy initiator in glioblastoma via the p-STAT3-MIR155-3p-CREBRF pathway. Autophagy. 2016; 12(7):1129-52

243. Chakrabarti M, Klionsky DJ, Ray SK. miR-30e blocks autophagy and acts synergistically with proanthocyanidin for inhibition of AVEN and BIRC6 to increase apoptosis in glioblastoma stem cells and glioblastoma SNB19 cells. PLoS One. 2016;11(7):e0158537.
244. Chen P-H, Cheng C-H, Shih C-M, Ho K-H, Lin C-W, Lee C-C, Liu A-J, Chang C-K, Chen K-C. The inhibition of microRNA-128 on IGF-1-activating mTOR signaling involves in temozolomide-induced glioma cell apoptotic death. PLoS One. 2016;11(11):e0167096.

245. Zhou W, Liu L, Xue Y, Zheng J, Liu X, Ma J, Li Z, Liu Y. Combination of endothelial-monocyte-activating polypeptide-II with Temozolomide suppress malignant biological behaviors of human glioblastoma stem cells via miR-590-3p/MACC1 inhibiting PI3K/AKT/mTOR signal pathway. Front Mol Neurosci. 2017;10:68.

246. Wang Z, Deng M, Liu Z, Wu S. Hypoxia-induced miR-210 promoter demethylation enhances proliferation, autophagy and angiogenesis of schwannoma cells. Oncol Rep. 2017;37(5):3010-8.

247. Pannuru P, Dontula R, Khan AA, Herbert E, Ozer H, Chetty C, Lakka SS. miRlet-7f-1 regulates SPARC mediated cisplatin resistance in medulloblastoma cells. Cell Signal. 2014;26(10):2193-201.

248. Jiang C, Shen F, Du J, Fang X, Li X, Su J, Wang X, Huang X, Liu Z. Upregulation of CASC2 sensitized glioma to temozolomide cytotoxicity through autophagy inhibition by sponging miR-193a-5p and regulating mTOR expression. Biomed Pharmacother. 2018;97:844-50.

\section{Publisher's Note}

Springer Nature remains neutral with regard to jurisdictional claims in published maps and institutional affiliations.

Ready to submit your research? Choose BMC and benefit from:

- fast, convenient online submission

- thorough peer review by experienced researchers in your field

- rapid publication on acceptance

- support for research data, including large and complex data types

- gold Open Access which fosters wider collaboration and increased citations

- maximum visibility for your research: over $100 \mathrm{M}$ website views per year

At $\mathrm{BMC}$, research is always in progress.

Learn more biomedcentral.com/submissions 